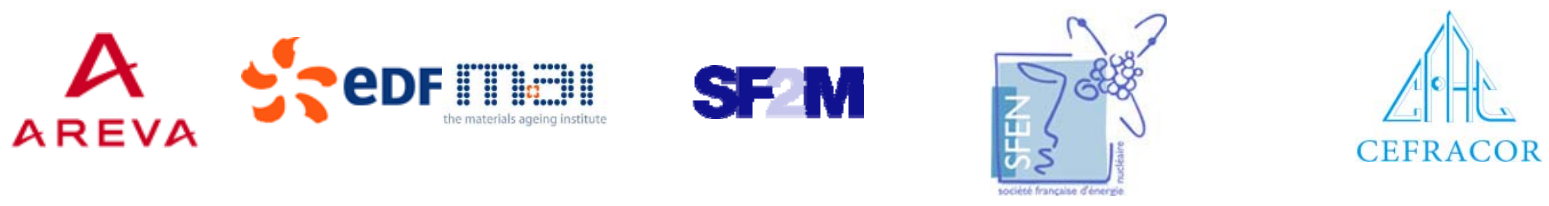

\section{MIN口S}

Centre of Excellence for Nuclear Materials

\section{Workshop}

Materials Innovation for Nuclear Optimized Systems
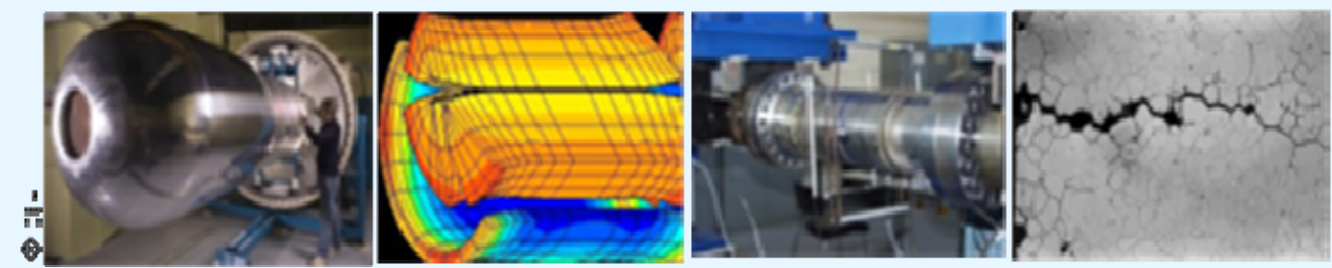

December 5-7, 2012, CEA - INSTN Saclay, France

\section{Steven J. ZINKLE}

Oak Ridge National Laboratory (USA)

Opportunities and Challenges for Materials Innovation in Nuclear Energy

Workshop organized by:

Christophe GALLÉ, CEA/MINOS, Saclay - christophe.galle@cea.fr Constantin MEIS, CEA/INSTN, Saclay - constantin.meis@cea.fr 


\title{
Opportunities and Challenges for Materials Innovation in Nuclear Energy
}

\author{
Steven J. ZINKLE ${ }^{1}$ \\ ${ }^{1}$ Oak Ridge National Laboratory (Oak Ridge, Tennessee, USA)
}

\begin{abstract}
Materials performance is central to the satisfactory operation of current and future nuclear energy systems. For example, the remarkable improvement in the operation and reliability of Generation-II light water reactors (LWRs) over the past 25 years has been largely associated with improvements in steam generator materials, fuel cladding technology (composition and fabrication), and improved understanding of water chemistry impacts on corrosion and deposition. Future fission and proposed fusion energy systems will be increasingly dependent on advanced structural materials to reliably deliver high performance with favorable safety attributes and acceptable economic cost. In many cases, the proposed operating temperatures are significantly higher than the experience base for light water reactors. This motivates development of structural materials with improved high temperature strength for prolonged operating periods and engineered corrosion resistance for the candidate coolants and other materials in the system. The high radiation fluxes in future nuclear energy systems will require the structural materials to have superior radiation resistance compared to currently available materials. The material performance demands are particularly challenging for the fuel cladding and wrapper of next-generation sodium-cooled fast reactors, where simultaneous resistance to high temperature thermal creep and radiation-induced property degradation up to doses of $\sim 100-150 \mathrm{dpa}$ is required.
\end{abstract}

Several strategies can be utilized to develop structural materials with simultaneous high radiation resistance, high strength, good toughness and corrosion resistance, and moderate fabrication cost. There are three general approaches for designing radiation resistance: Nanoscale precipitates or interfaces to produce high point defect sink strength (e.g., oxide dispersion strengthened (ODS) and next-generation ferritic/martensitic steels with high particle densities); purposeful utilization of immobile vacancies (e.g., SiC/SiC ceramic composites); and utilization of radiation-resilient matrix phases (e.g., ferritic instead of austenitic steel matrix, etc.). High-performance steels designed using computational thermodynamics are demonstrating promising capability to produce a high density of highly stable nanoscale precipitates that could serve as efficient point defect recombination centers during irradiation, and also provide good thermal creep strength at high temperatures [1]. Figure 1 shows an example of improvements in high temperature thermal creep properties for a $9 \% \mathrm{Cr}-1 \% \mathrm{Mo}$ ferritic martensitic steel that was achieved simply by slightly altering the thermomechanical processing procedure. Figure 2 compares the fracture toughness behavior of an advanced ODS ferritic steel before and after low dose neutron irradiation at $300^{\circ} \mathrm{C}$ [2]. The ductile to brittle transition temperature (DBTT) in the LT orientation remained below $-150^{\circ} \mathrm{C}$ with a shift in the DBTT of about $12^{\circ} \mathrm{C}$; the corresponding shift in the DBTT for EUROFER97 (9Cr-2WVTa) ferritic/martensitic steel was about $39^{\circ} \mathrm{C}$. Higher dose studies are in progress.

It will be important for nuclear energy researchers to continue to closely interact with the broader materials science and engineering community in order to effectively leverage innovations that continue to occur in the broad field of materials science. For example, practical aspects used in the aerospace industry to reduce the time from invention of a new alloy system to code qualification and commercialization could be useful for development of new structural materials for nuclear energy systems. In the future, utilization of emerging advanced manufacturing processes such as additive manufacturing to produce near-net shape parts with precise microstructural control will be of increasing importance to control fabrication costs and to create high-performance fabrication architectures that could not be achieved using conventional fabrication methods. 
Following the accident at the Fukushima Daiichi site in Japan, there is increasing interest in exploring accident tolerant or enhanced safety margin fuel systems for existing and future reactors, which could potentially provide increased response time or reduced consequences via reduced enthalpy production, reduced hydrogen production, and delayed clad rupture or fission product release during a loss of coolant accident compared to conventional $\mathrm{Zr}$ alloy cladding/ monolithic $\mathrm{UO}_{2}$ fuel systems. Although all alternative fuel systems have technological or neutronic shortcomings, exploratory research would be useful to quantify their potential improved accident tolerance so that an informed decision on the best option(s) for future LWR fuel systems can be reached. If research results on a particular accident tolerant concept prove to be promising, it might be possible to initiate confirmatory tests in commercial reactors within about 10 years.

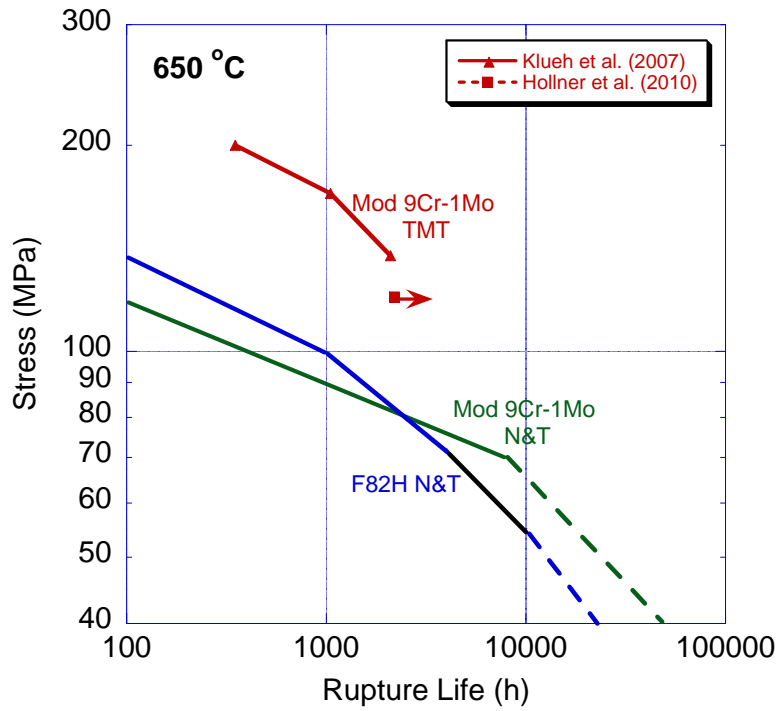

Fig. 1: Comparison of creep rupture behavior of $9 \% \mathrm{Cr}$ steels at $650^{\circ} \mathrm{C}$ after conventional and new thermomechanical treatment [1].

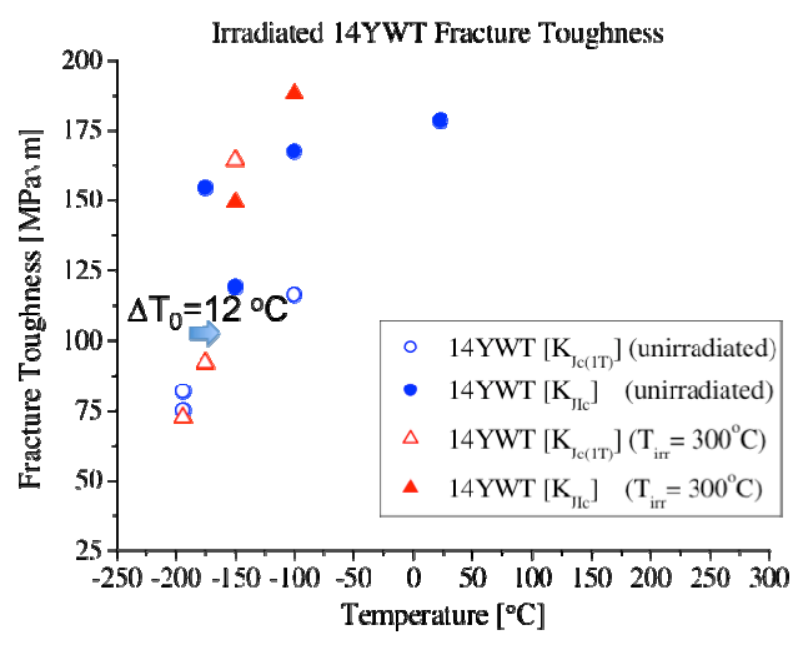

Fig. 2 : Comparison of the fracture toughness of 14YWT ODS ferritic steel before and after neutron irradiation to $1.5 \mathrm{dpa}$ at $300^{\circ} \mathrm{C}$ [2].

\section{References}

[1] S.J. Zinkle, N.M. Ghoniem. J. Nuclear Materials 417 (2011) 2.

[2] D.A. McClintock, M.A. Sokolov, D.T. Hoelzer, R.K. Nanstad.J. Nuclear Materials 392 (2009) 353. 


\section{Opportunities and Challenges for Materials Innovation Nuclear Energy}

\section{Steven J. Zinkle}

Oak Ridge National Laboratory

Oak Ridge, Tennessee, USA

Workshop on Materials Innovation for Nuclear Optimized Systems

INSTN-CEA Saclay, France

December 5-7, 2012 


\section{Overview of Challenges and Opportunities}

- Many commercial alloys are operating near their performance limits and exhibit variable heat-to-heat performance

- Artifacts of empirical/evolutionary approach to developing new alloys

- Future goals for nuclear energy involve even more extreme operating environments

- Plant life extensions for LWRs

- Gen IV fission and fusion reactors (higher doses and temperatures)

- The accident at the Fukushima Dai-ichi power plant is causing some nations to reconsider the future of nuclear energy

- Recent results suggest combination of new tools such as computational thermodynamics and knowledge of degradation mechanisms (creep-fatigue, radiation effects, etc.) can be used to design very high-performance materials 


\section{Comparison of Gen IV and Fusion Structural Materials Environments}

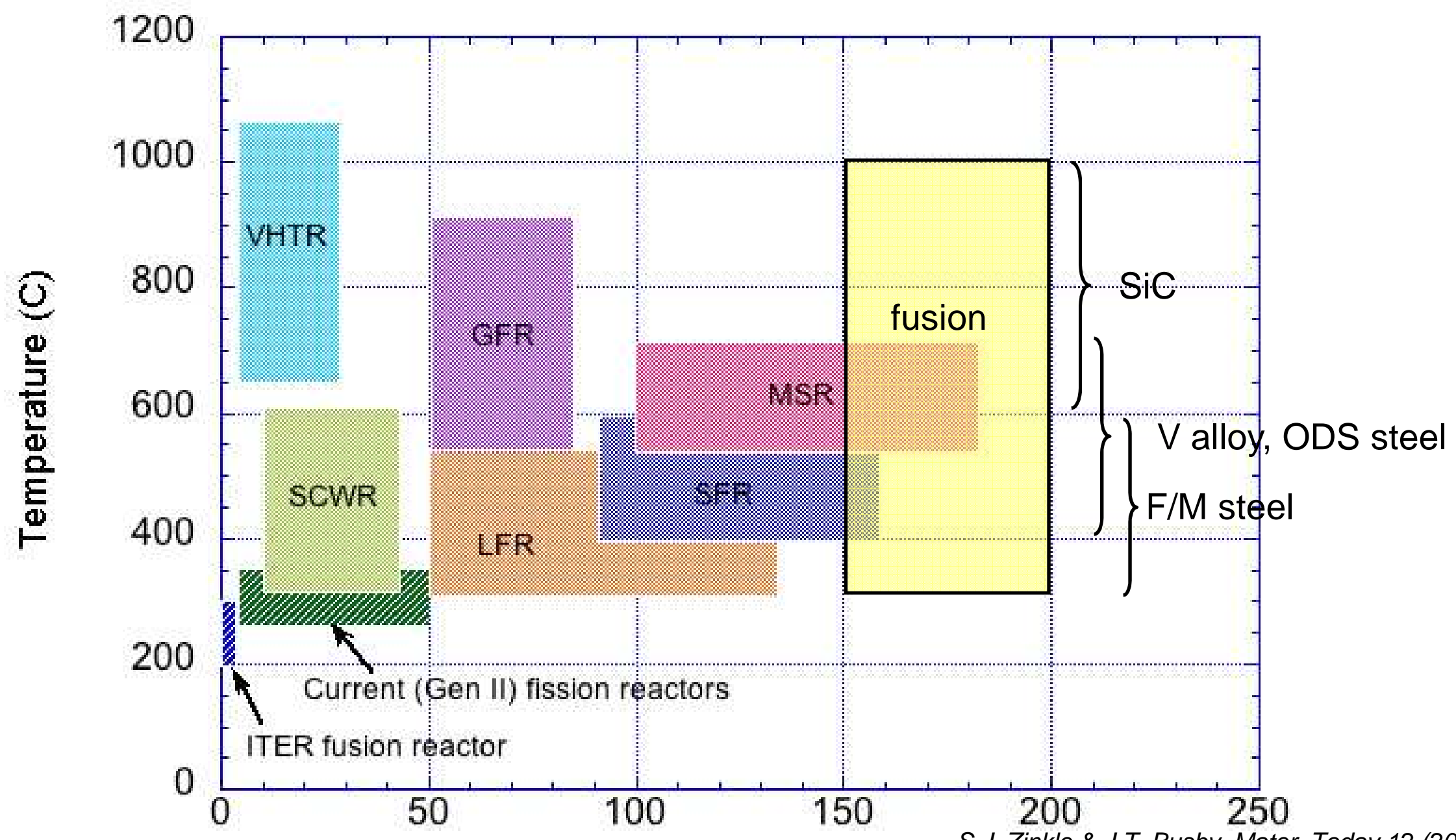

Displacement Damage (dpa) S.J. Zinkle, OECD NEA Workshop on Structural Materials for Innovative Nuclear Energy Systems, All Gen IV and Fusion concepts pose Karlsruhe, Germany, June 2007 


\section{Heat to Heat Variability has been a Common Feature of Structural Alloys}

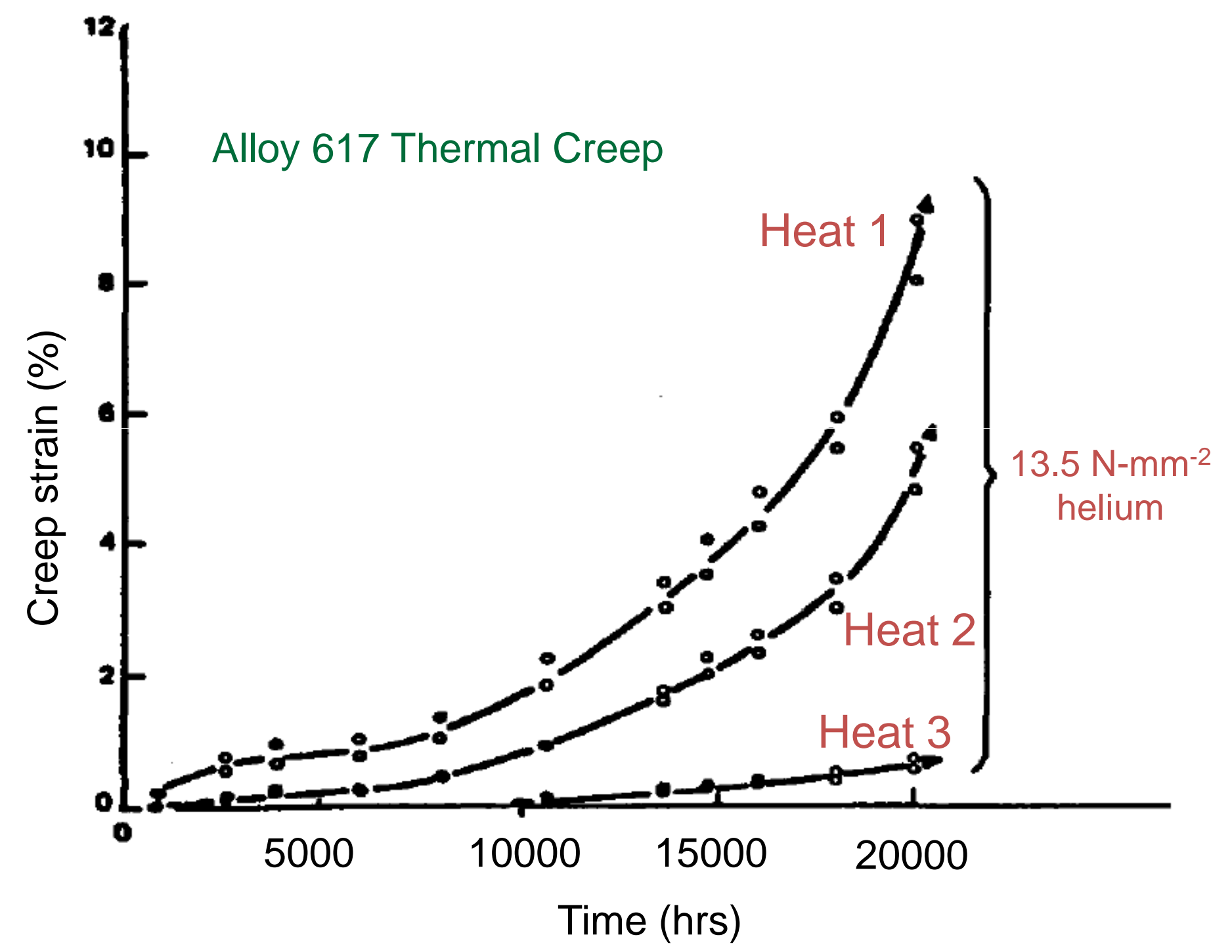


Today We Know That Very Long Time Service Causes The Properties of $9 \mathrm{Cr}-1 \mathrm{MoVNb}$ to Decrease to a Greater Extent Than Anticipated In Initial Alloy Design

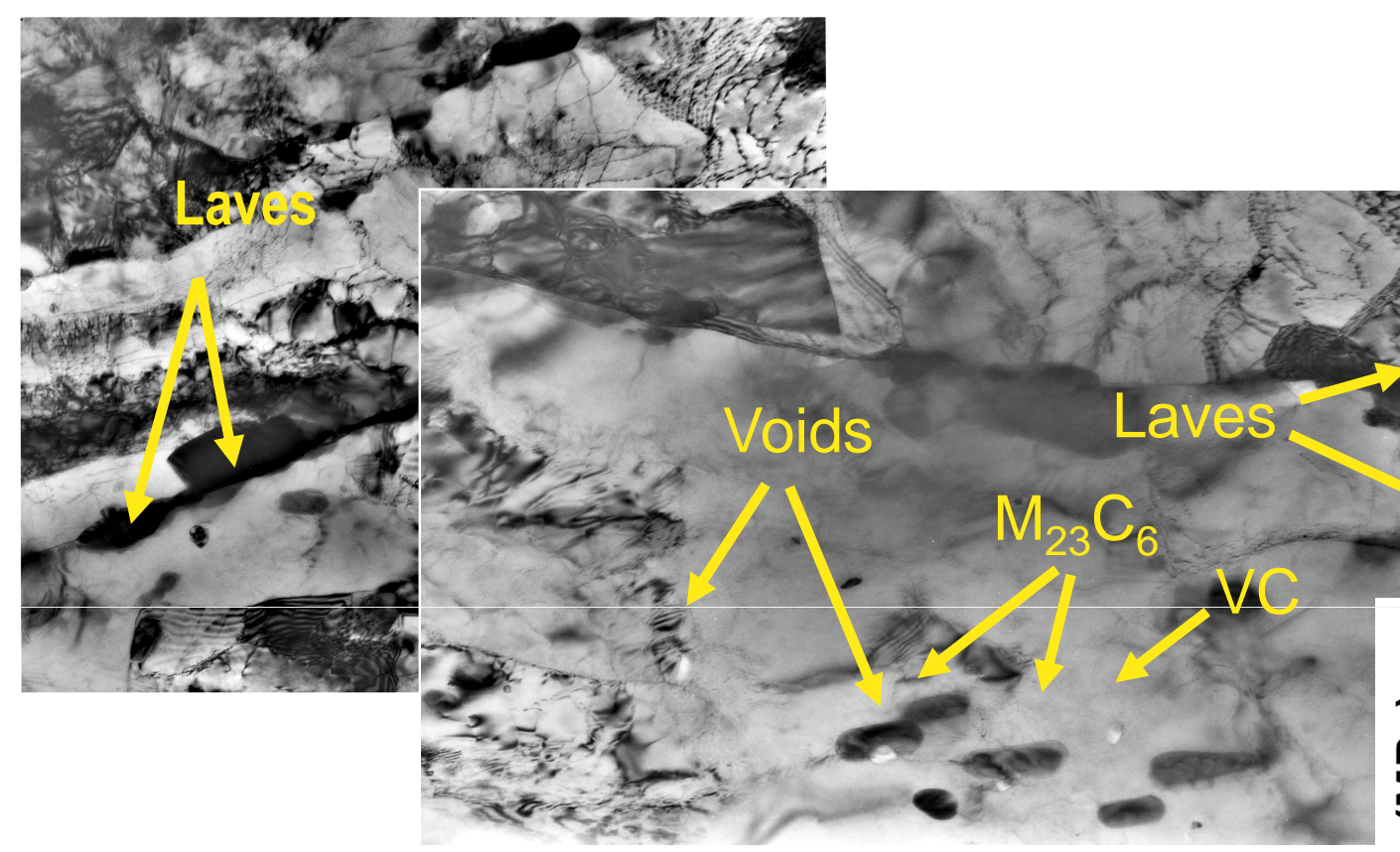

The Tensile Strength of $9 \mathrm{Cr}-1 \mathrm{MoVNb}$ Decreased 15\% As A Result Of Long-Time Steam Boiler Tubing Service

Computational thermodynamics: $\sim 6.3 \%$ of ASME allowable compositions for grade 92 produced ferrite at the $1040^{\circ} \mathrm{C}$ normalizing temperature (Vitek \& Santella, ORNL)
Exposure of

$9 \mathrm{Cr}-1 \mathrm{MoVNb}$ Tubing for $155,000 \mathrm{~h}$ at $550-590^{\circ} \mathrm{C}$

Produces Laves Phase

Precipitation and

Substructure Recovery

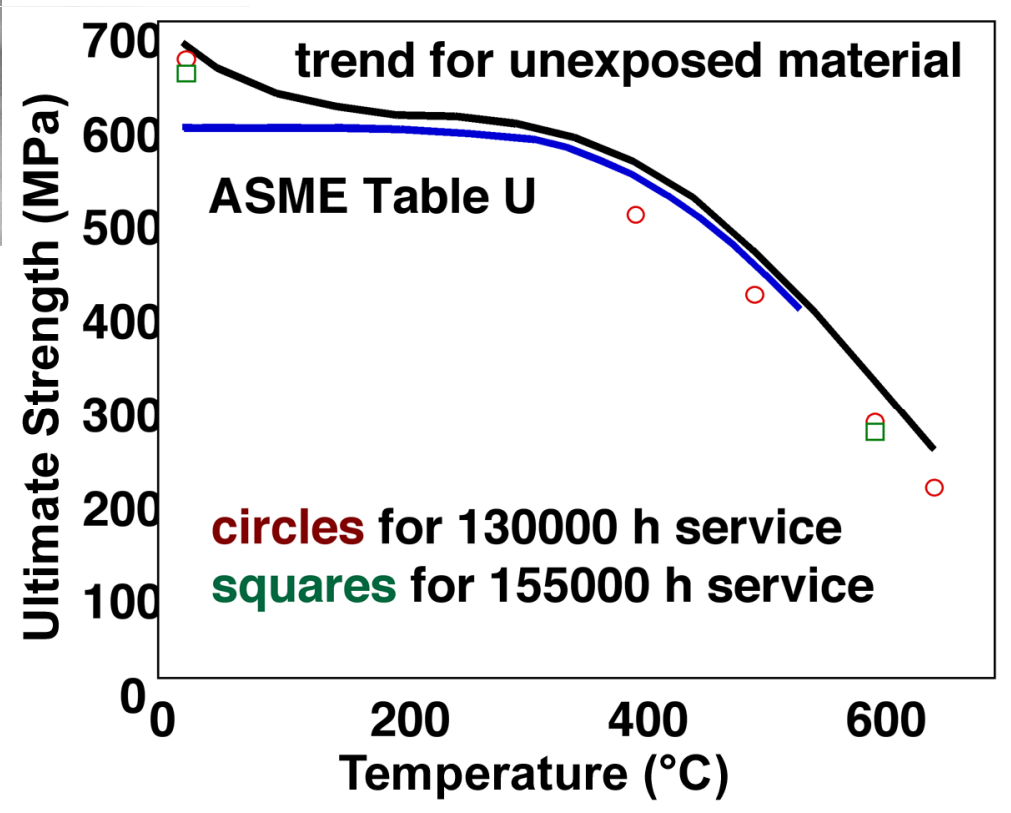

Results were consistent with expectations based on aging studies of Brinkman (ORNL) in 1990. 
Radiation Damage can Produce Large Changes in Structural Materials

- Radiation hardening and embrittlement $\left(<0.4 \mathrm{~T}_{\mathrm{M}}\right.$, $>0.1$ dpa)

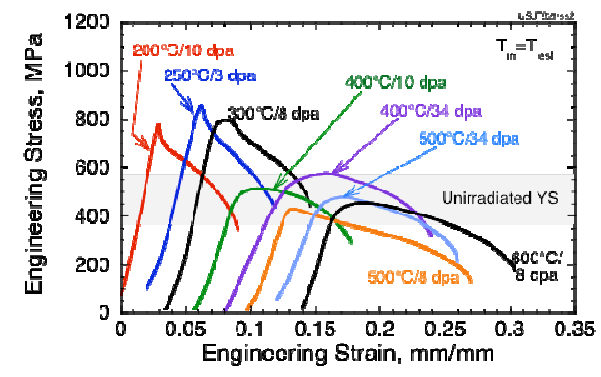

- Phase instabilities from radiation-induced precipitation (0.3-0.6 $\left.\mathrm{T}_{\mathrm{M}},>10 \mathrm{dpa}\right)$

- Irradiation creep $\left(<0.45 \mathrm{~T}_{\mathrm{M}},>10 \mathrm{dpa}\right)$

- Volumetric swelling from void formation (0.3-0.6 $\left.\mathrm{T}_{\mathrm{M}},>10 \mathrm{dpa}\right)$
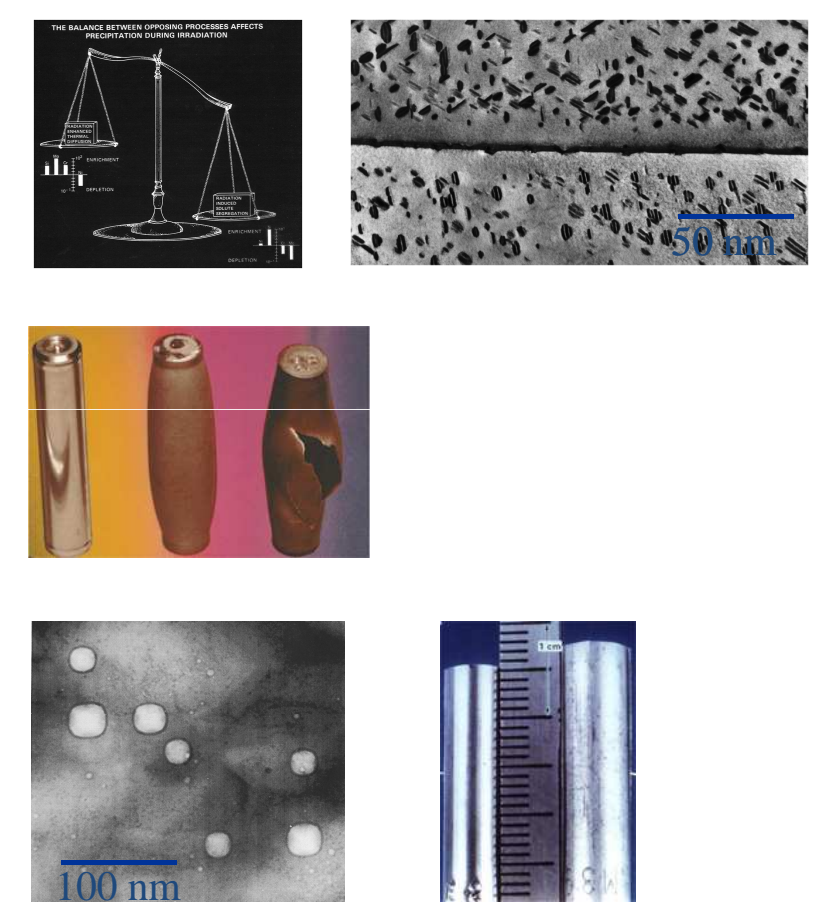

- High temperature He embrittlement $\left(>0.5 T_{M}\right.$, $>10$ dpa)

S.J. Zinkle, Phys. Plasmas 12 (2005) 058101; Zinkle \& Busby, Mater. Today 12 (2009) 12

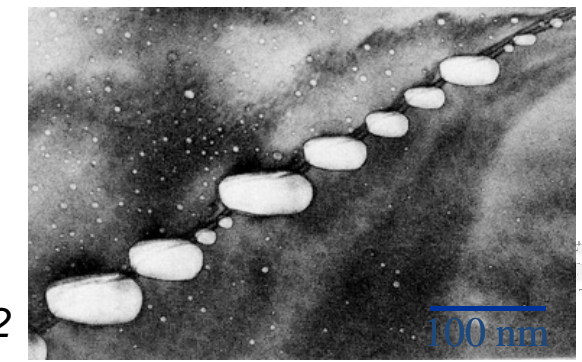




\section{Examples of radiation damage degradation in steels}

Fracture toughness of Types 304 and 316 stainless steel irradiated at $250-350 \mathrm{C}$

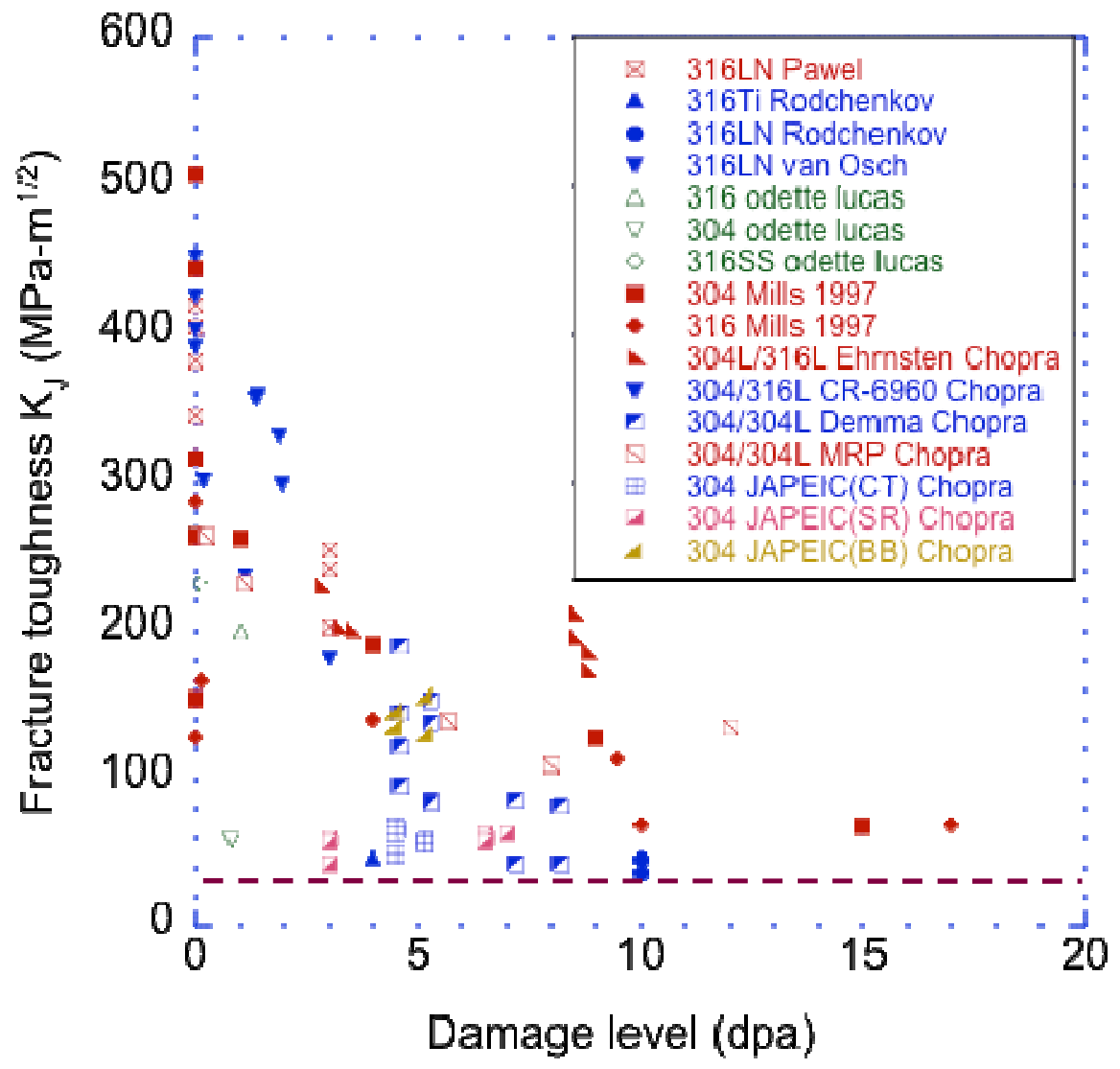

Contributor to SCC in LWR internals
Comparison of Volumetric Swelling in Fast Fission Reactor Irradiated Austenitic and Ferritic-Martensitic Steels

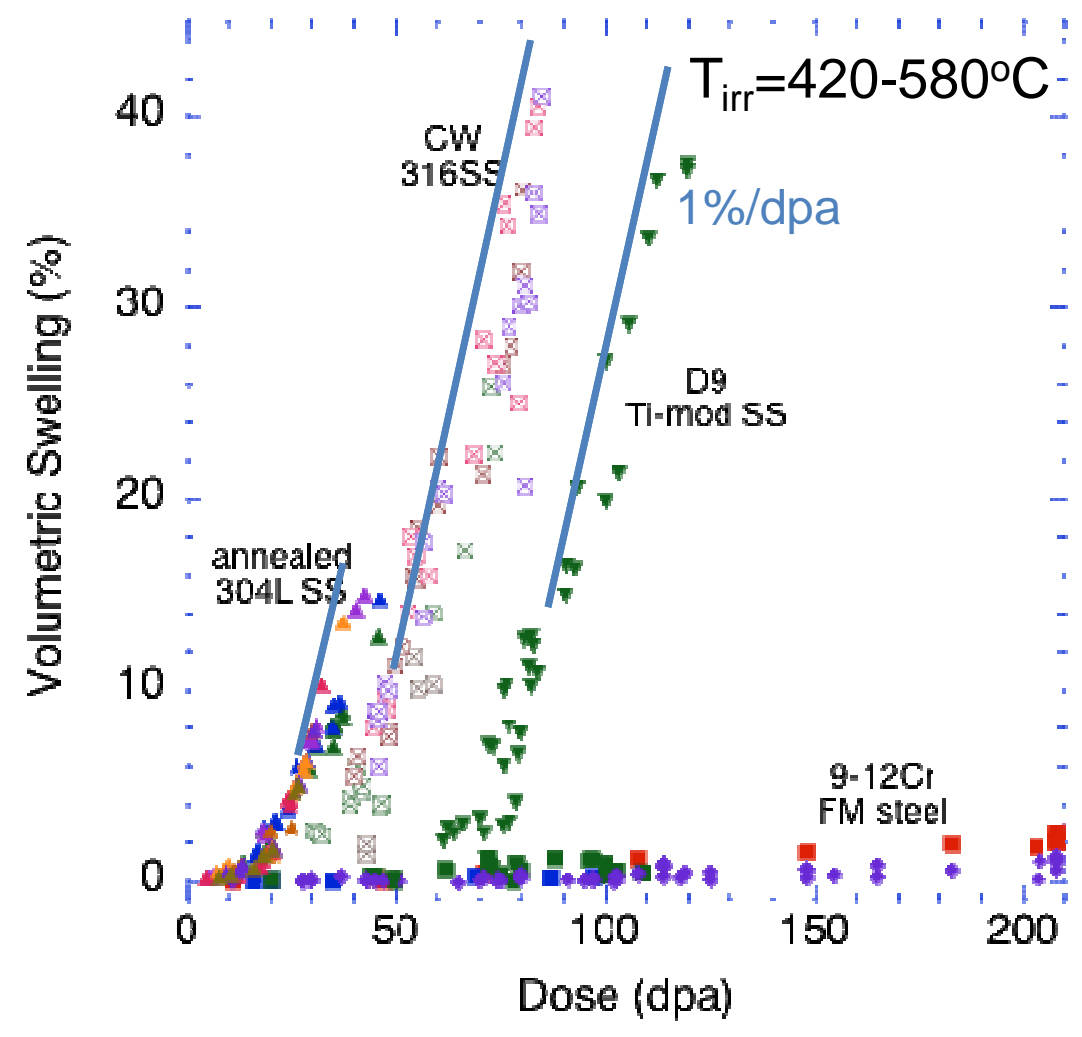

Conventional stainless steels are not attractive options for high dose Gen IV reactor applications 
Cavity swelling in neutron-irradiated $8-9 \% \mathrm{Cr}$ reduced activation ferritic-martensitic steels may become significant for fusion-relevant $\mathrm{He} / \mathrm{dpa}$ values

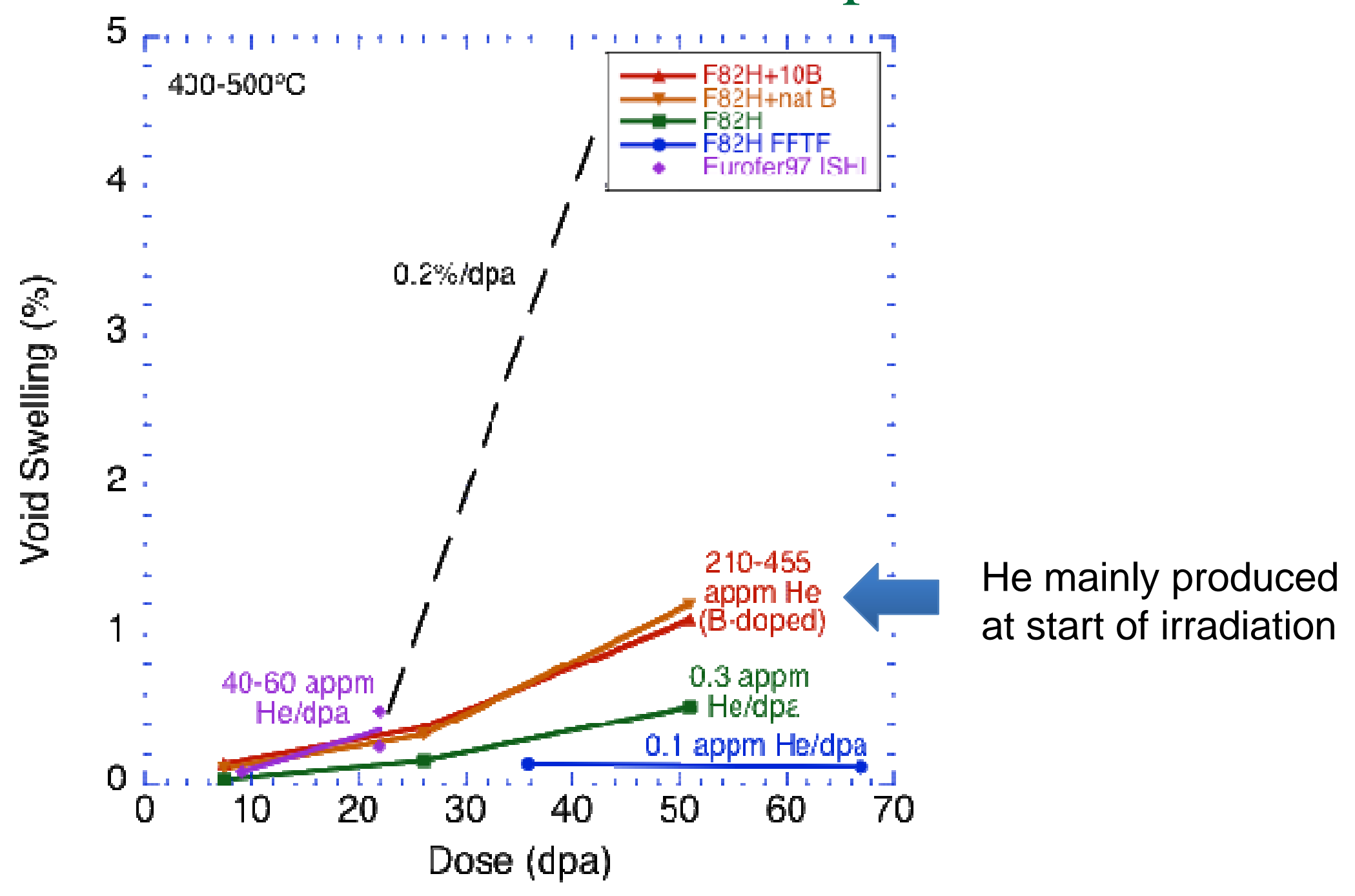

S. Zinkle, A. Möslang, T. Muroga \& H. Tanigawa, IAEA Fusion Energy Conf., 2012; Nucl. Fusion, in press 
Effect of Neutron Irradiation on the Ductile to Brittle Transition Temperature of Reduced Activation 9Cr Ferritic/Martensitic Steels

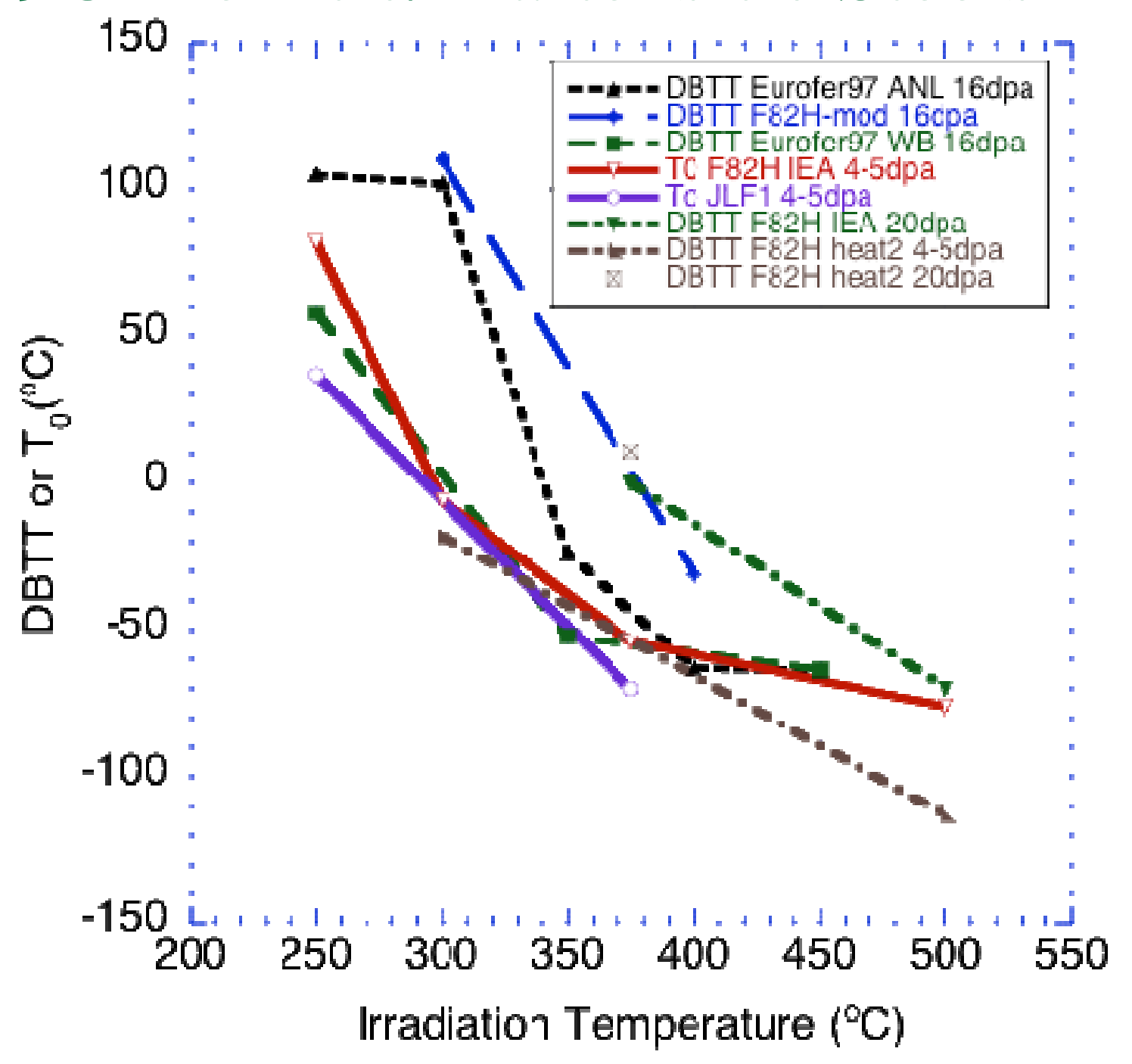
press (IAEA Fusion Energy Conference, San Diego, Oct. 2012) 


\section{Can we break the shackles that limit conventional structural materials to $\sim 300^{\circ} \mathrm{C}$ temperature window?}

Structural Material Operating Temperature Windows: 10-50 dpa

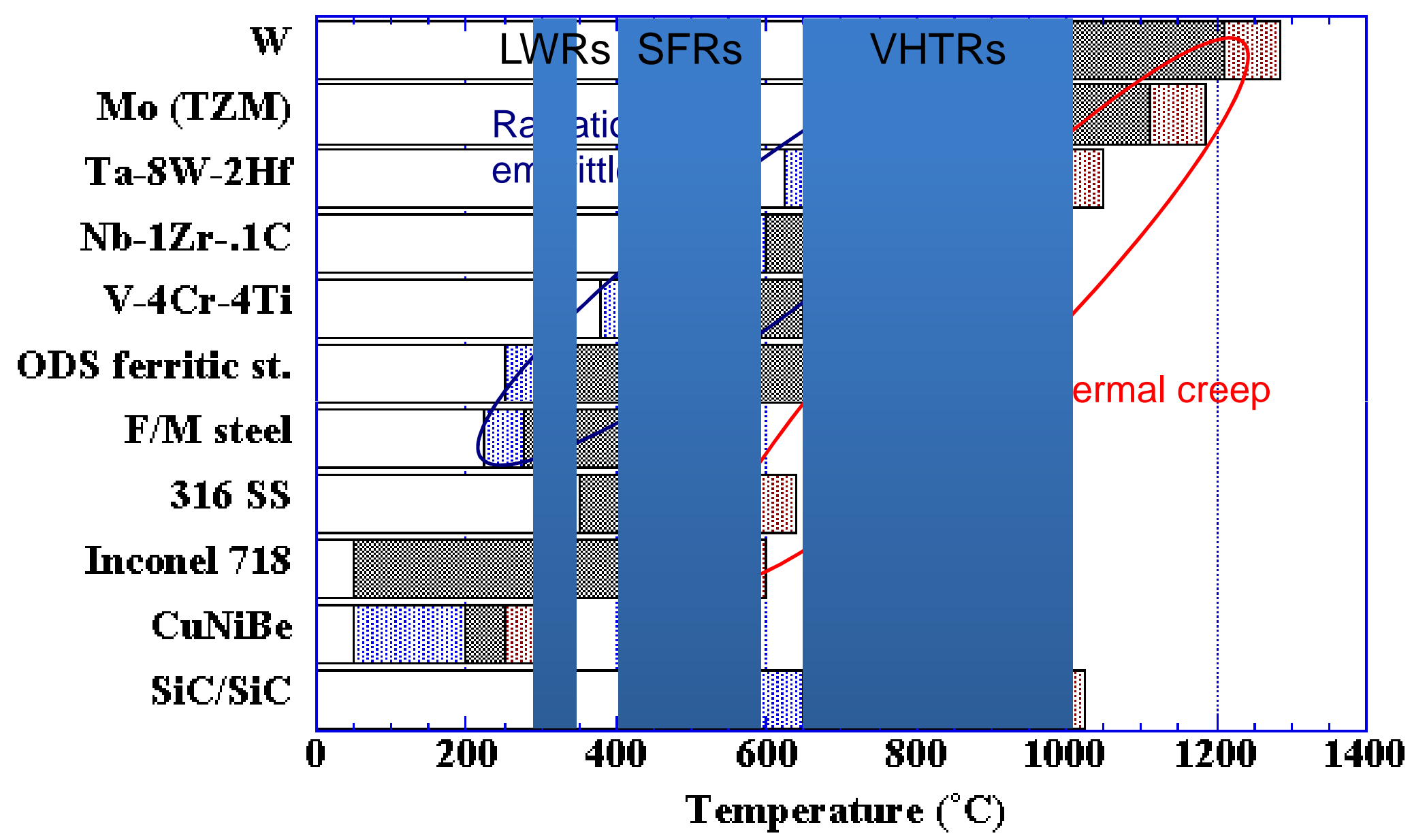

$\eta_{\text {Carnot }}=1-\mathrm{T}_{\text {reject }} / \mathrm{T}_{\text {high }}$

Additional considerations such as He embrittlement and chemical compatibility may impose further restrictions on operating window Zinkle and Ghoniem, Fusion Engr. Des. 49-50 (2000) 709 


\section{Approaches for radiation resistance 1: High sink strength}

- high density of nanoscale precipitates or particles (e.g., ODS steel or Ti-modified austenitic stainless steel)

High density of stable precipitates can also improve thermal creep strength

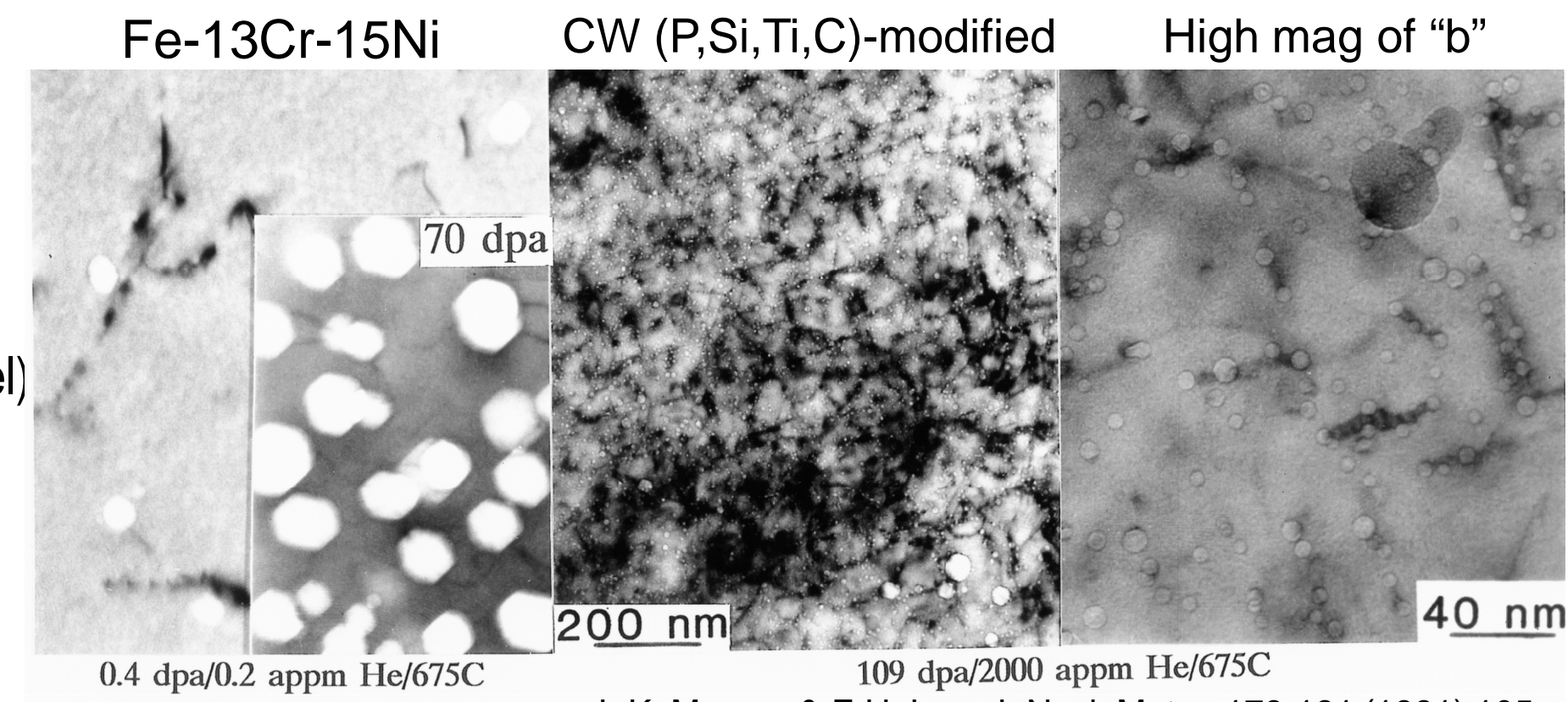

- High density of interfaces (grain boundaries or multilayers)
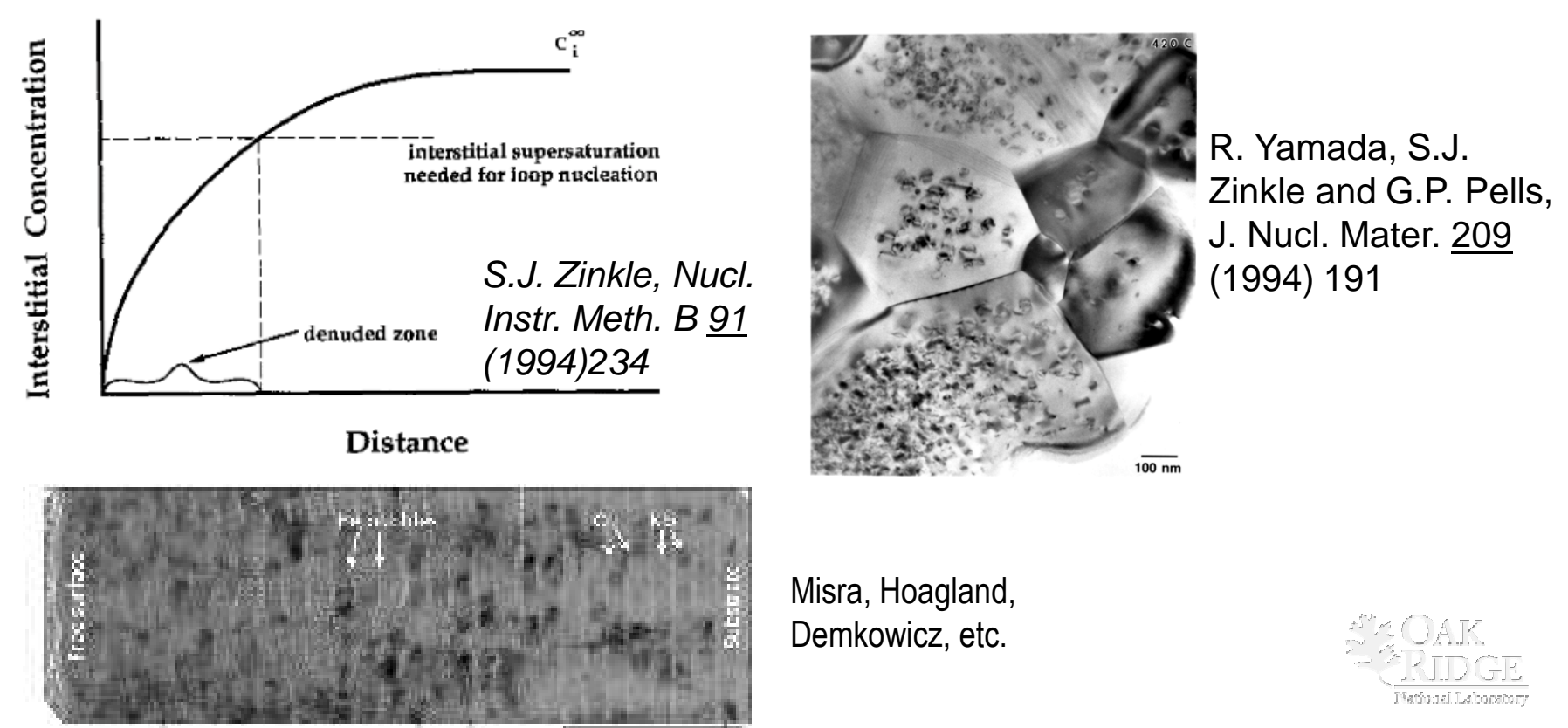

Misra, Hoagland,

Demkowicz, etc.

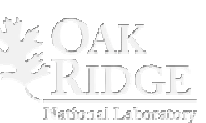


Effect of Initial Sink Strength on the Radiation Hardening of Ferritic/martensitic Steels

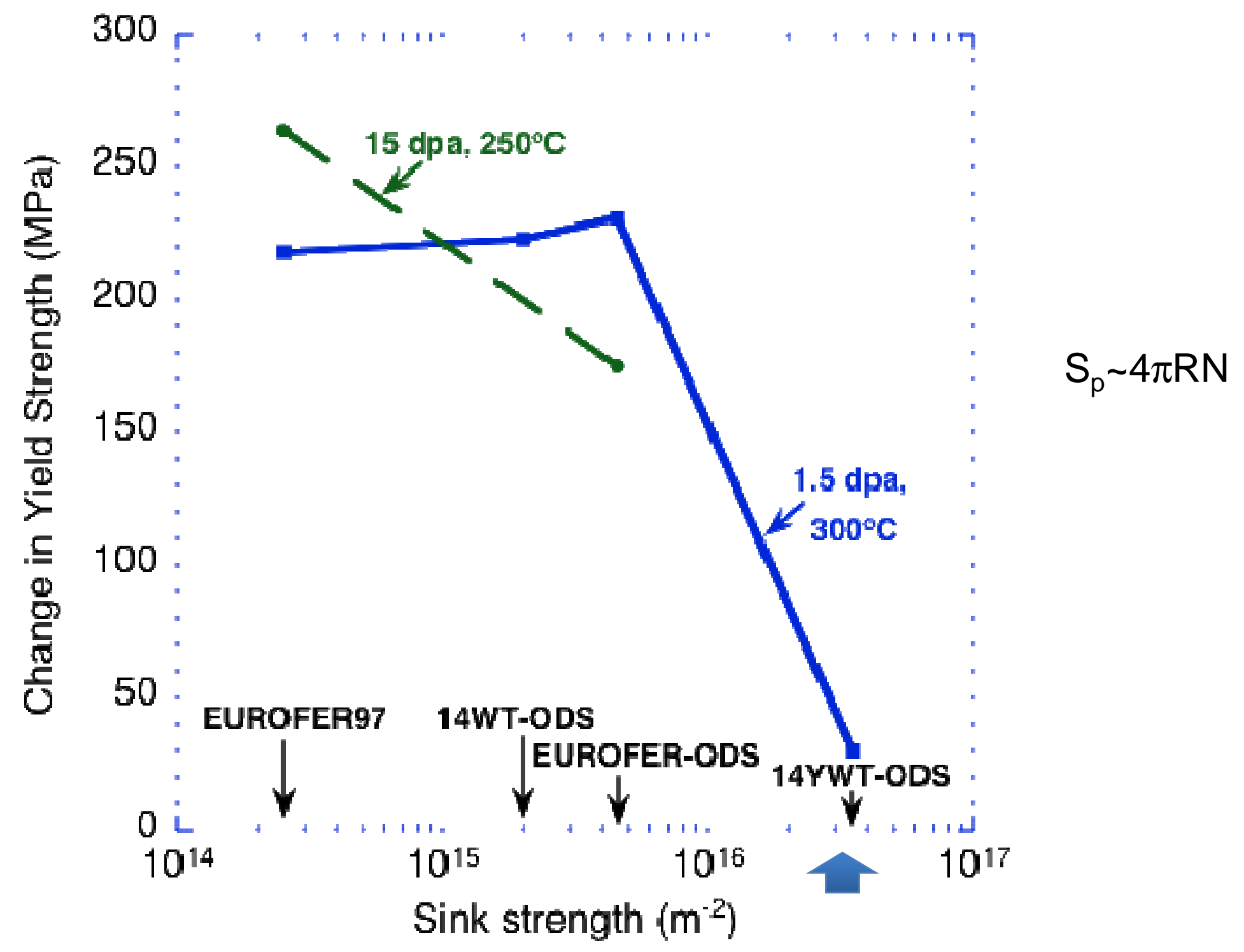
press (IAEA Fusion Energy Conference, San Diego, Oct. 2012) 


\section{Approaches for radiation resistance 2: Immobile defects}

- Defect accumulation is limited if one or more defect types are immobile

- Utilize materials with negligible point defect mobility at desired operating temperatures

- A key potential consequence (particularly in ordered alloys and ceramics) is amorphization, with accompanying significant volumetric and property changes

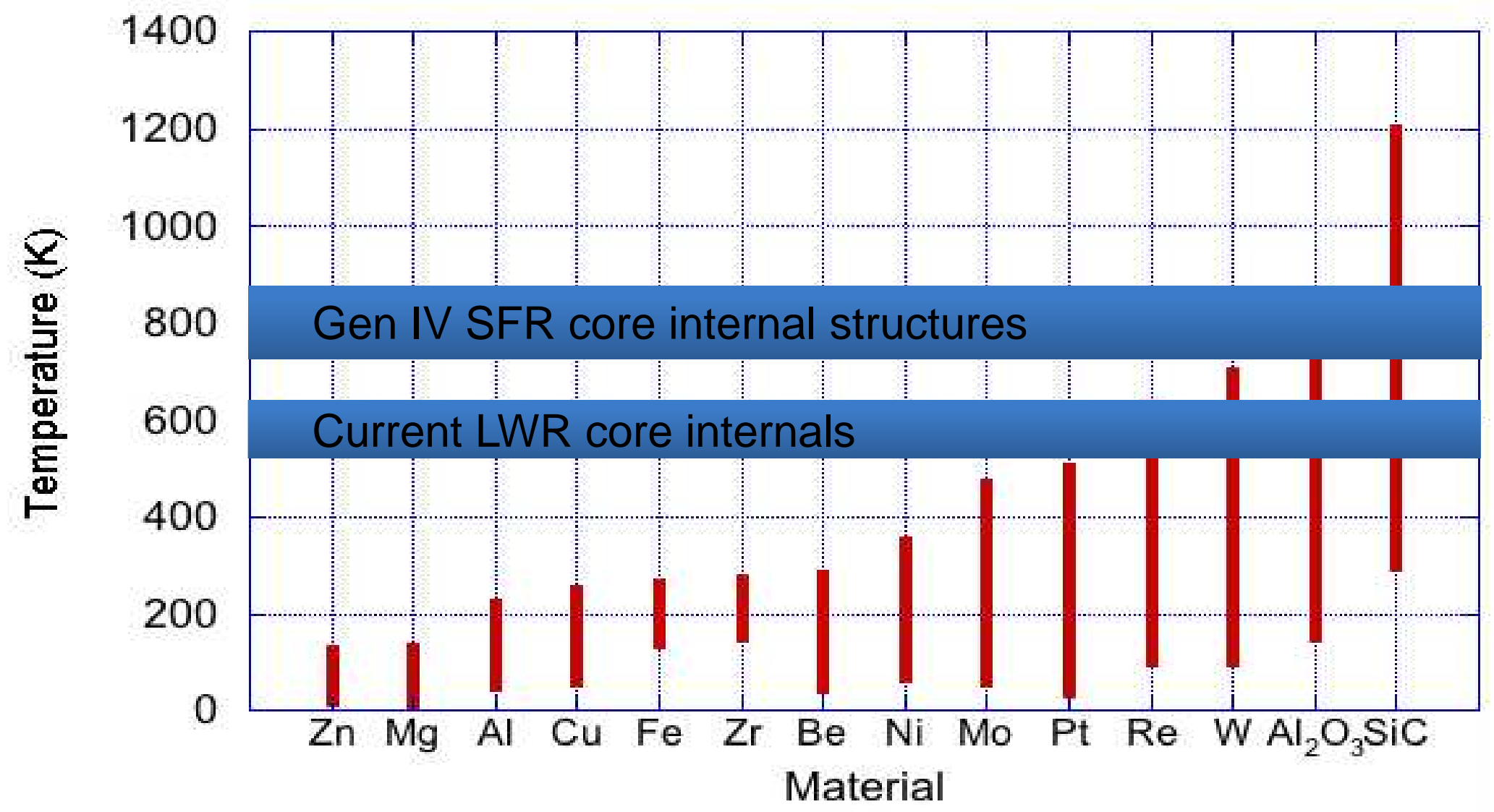

- Regime with intrinsically high point defect recombination typically occurs at too low of temperatures for power generation applications (except $\mathrm{SiC}$ and possibly $\mathrm{Al}_{2} \mathrm{O}_{3}, \mathrm{~W}, \mathrm{Re}$ ) after S.J. Zinkle, Chpt. 3 in Comprehensive Nuclear Materials (Elsevier, 2012) 


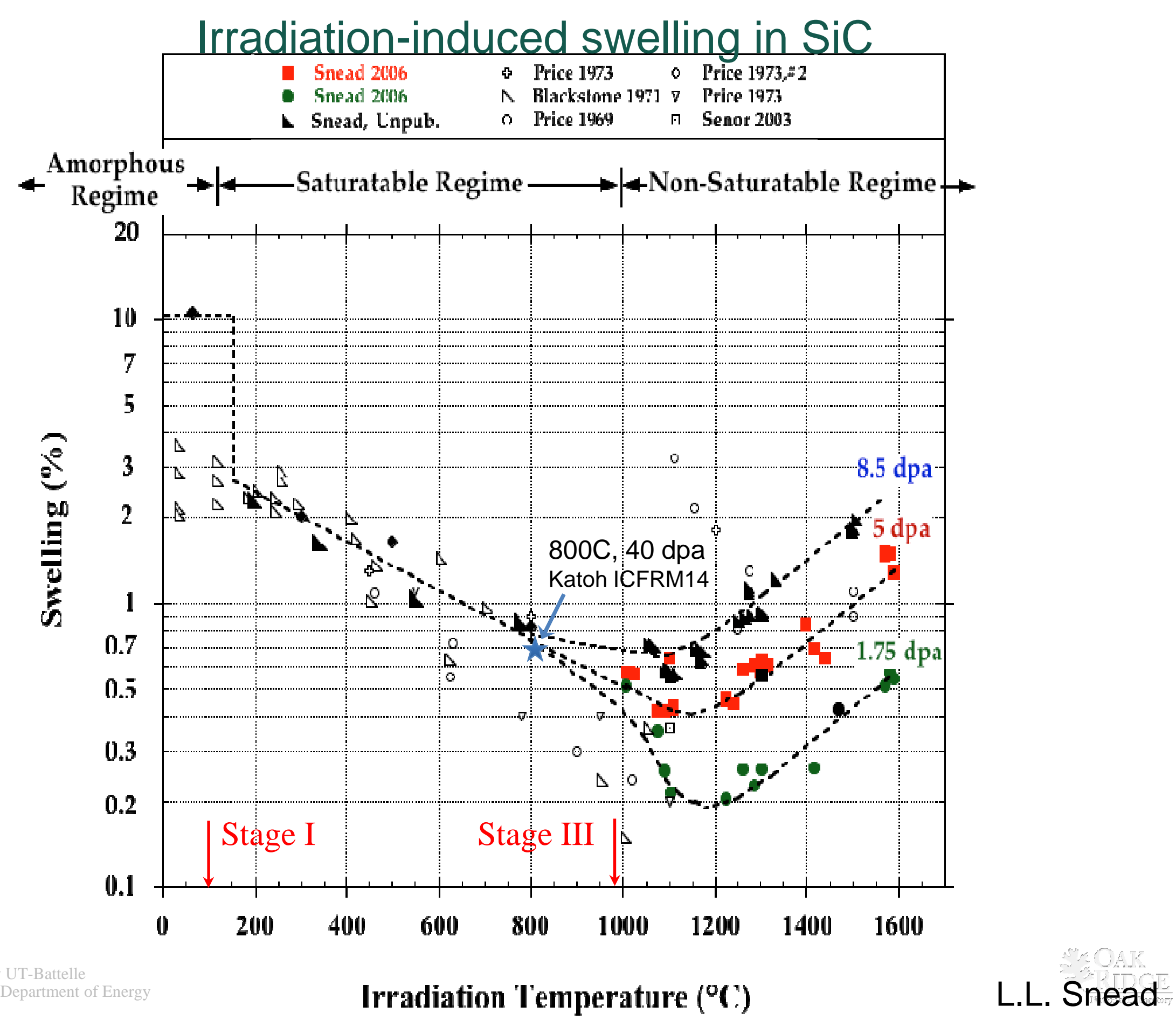


Approaches for radiation resistance 3: Utilize matrix phases that are resistant to defect accumulation (e.g., BCC or noncrystalline phases) MD: Large vacancy clusters are not directly formed in BCC metal displacement cascades

Void swelling in $\mathrm{Fe}$ is significantly less than in $\mathrm{Cu}$ for the same dose
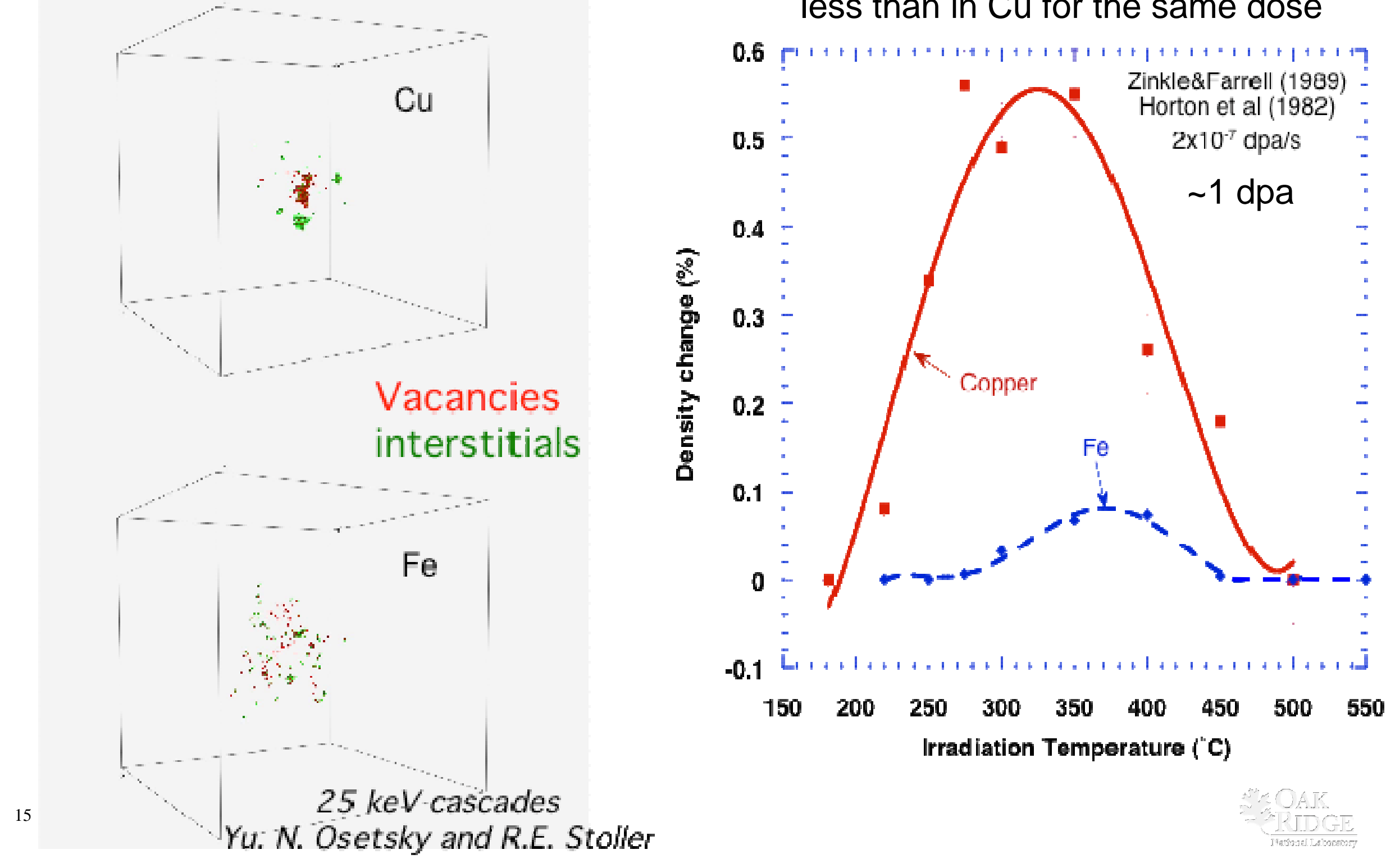


\section{Defect accumulation is lower in BCC steels compared to FCC}

Comparison of defect cluster formation in neutron irradiated austenitic and ferritic stainless steel $\left(0.065 \mathrm{dpa}, 120^{\circ} \mathrm{C}\right)$

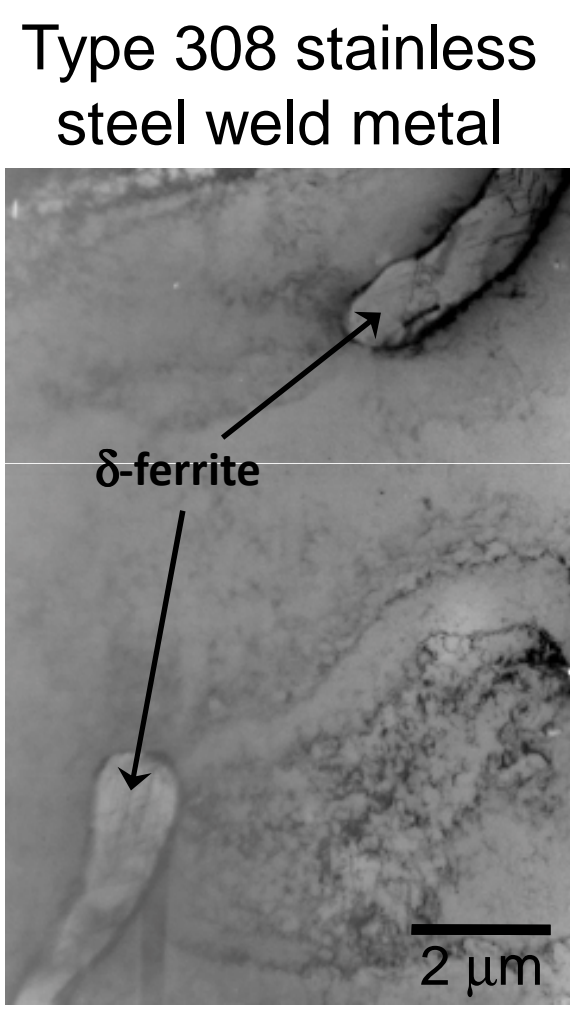

c $\delta$-ferrite
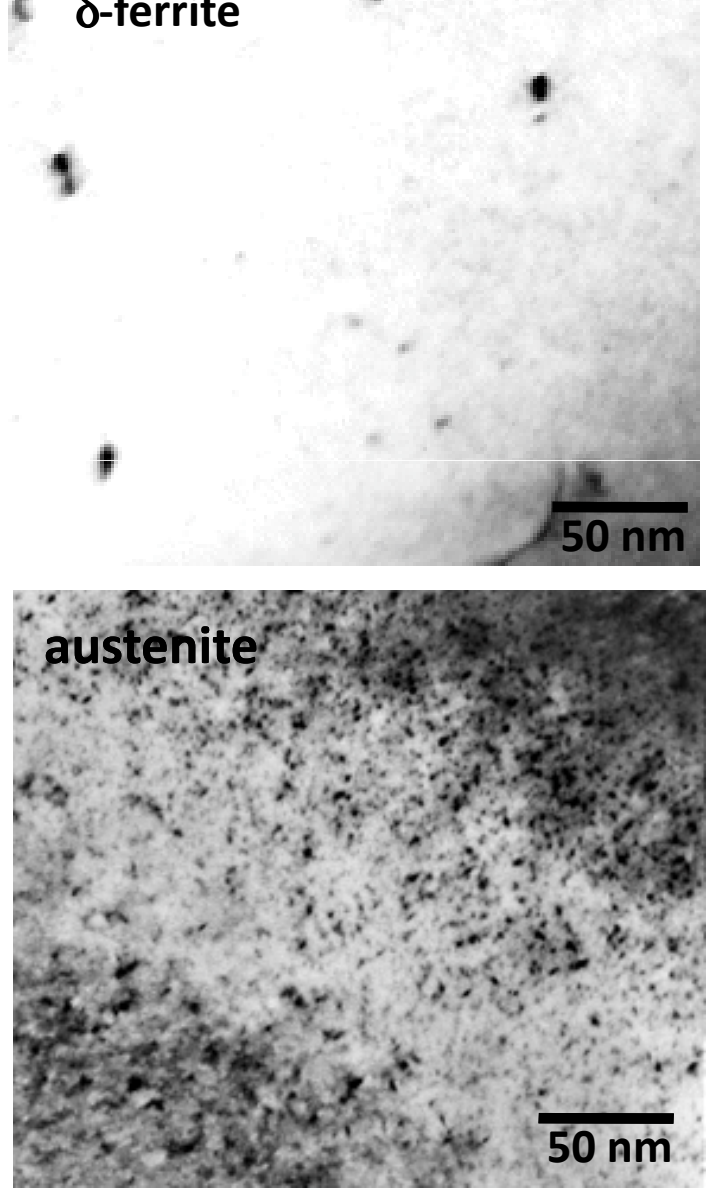

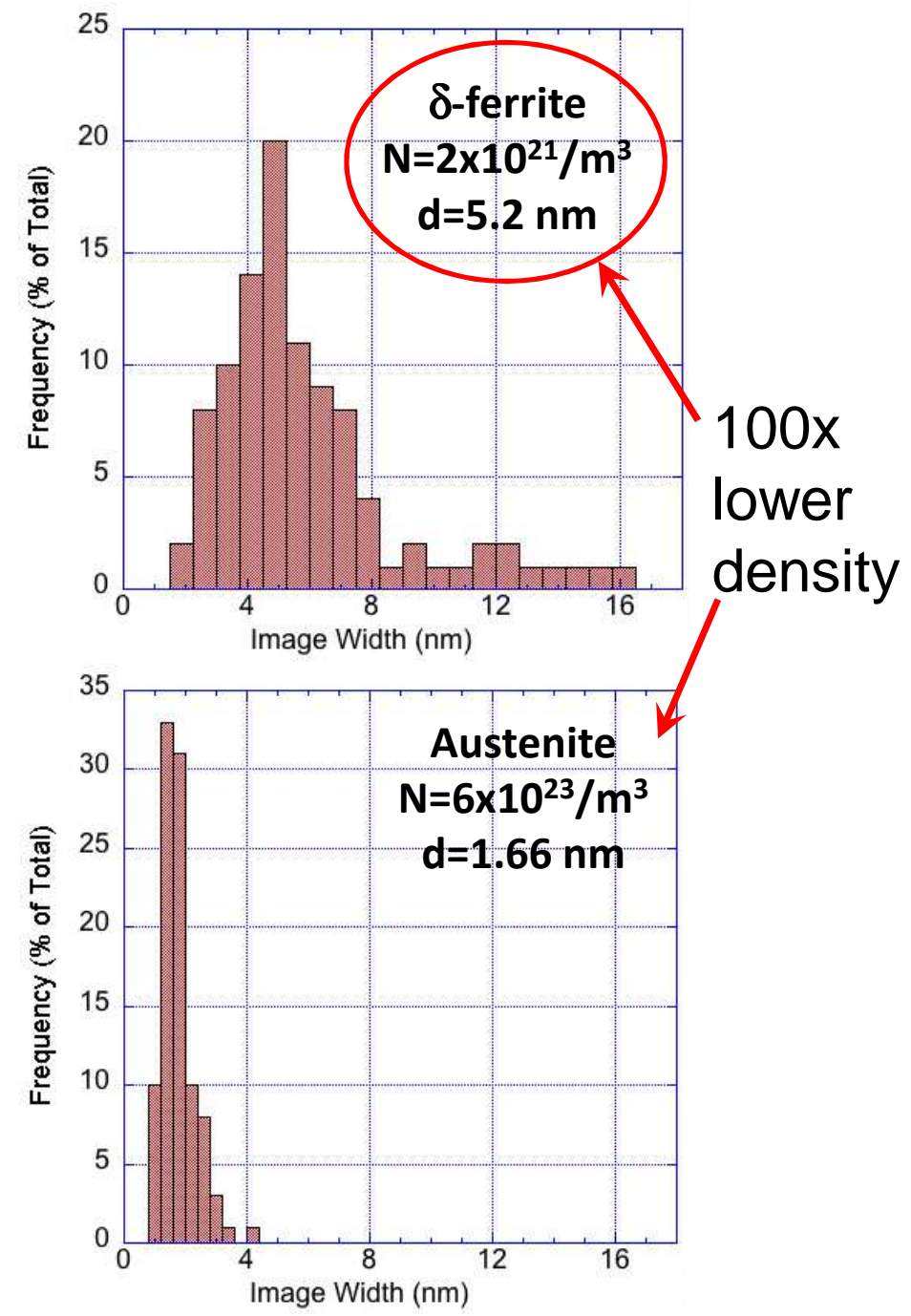

S.J. Zinkle \& R.L. Sindelar, unpublished 


\section{Modern steels exhibit reduced hardening and less embrittlement compared to 1960s-era RPV steel}

Hardening rate of $9 \mathrm{Cr}$ steels is about $50 \%$ that of RPV steels

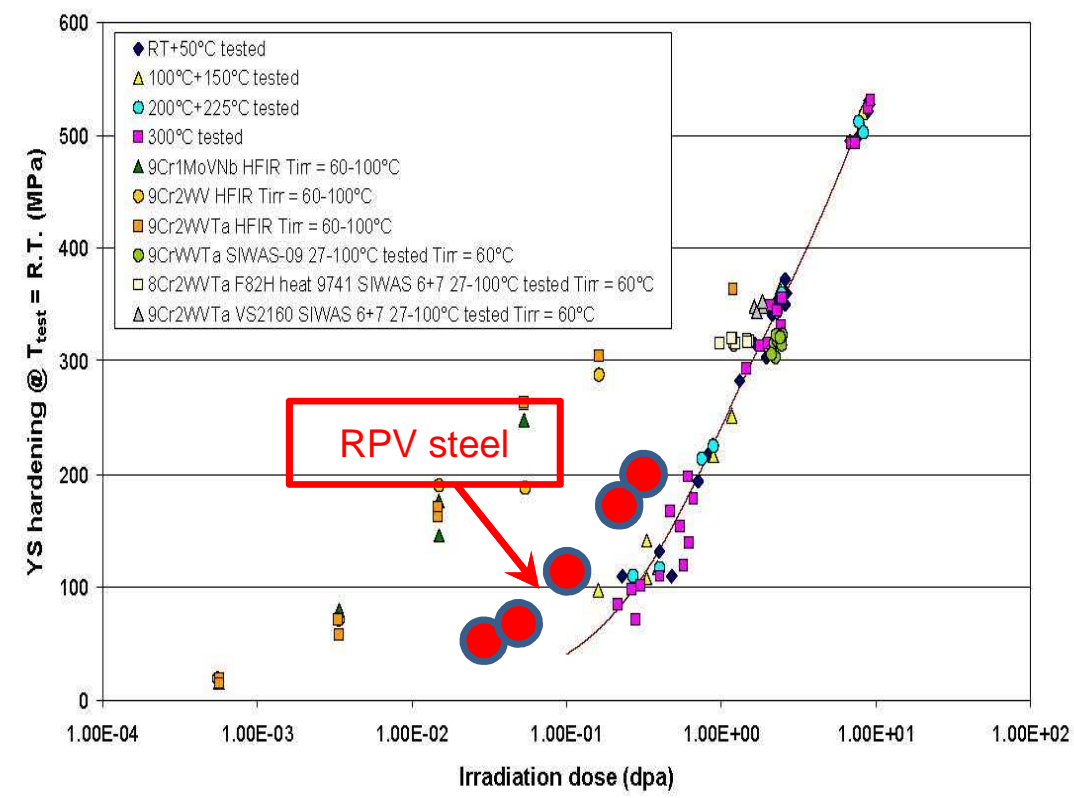

figure 70 Low temperature irradiation hardening of various $9 \mathrm{Cr}$ steels vs. dose at a log scale. NRG data from current report and [4], HFIR data from [26]

J. Rensman, NRG report 20023/05.68497/P (2005); M. Lambrecht et al., J. Nucl. Mater. 406 (2010) 84
Embrittlement rate of $9 \mathrm{Cr}$ steels is about $40 \%$ that of RPV steels (normalized to same amount of radiation hardening)

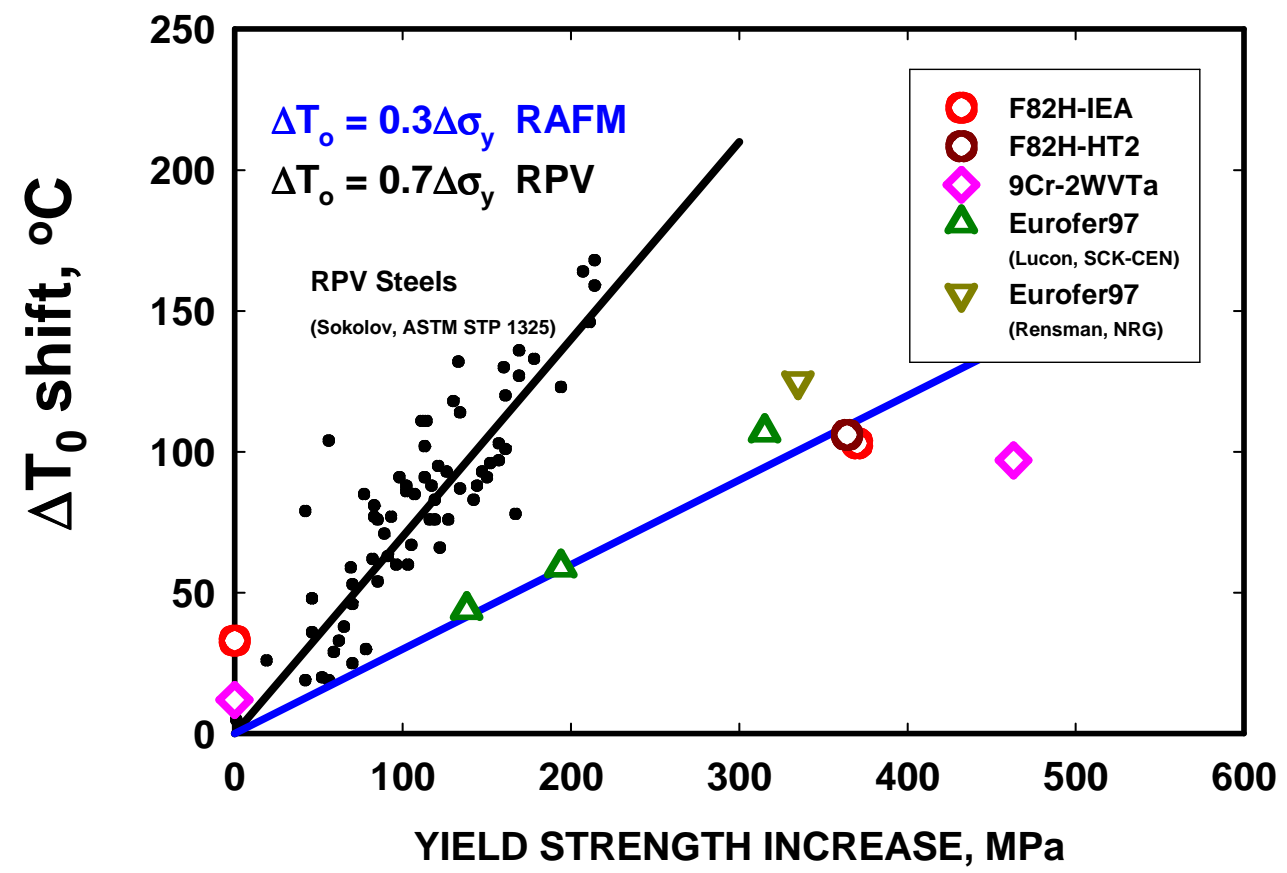

M.A. Sokolov et al., J. Nucl. Mater. $\underline{367-370}$ (2007) 68

Plotted data are $8-9 \%$ Cr steels; similar results obtained for

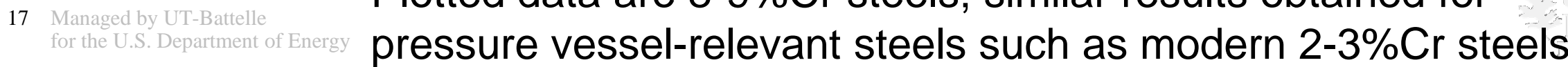




\section{New reduced activation steels designed with}

\section{computational thermodynamics exhibit superior}

\section{mechanical properties compared to conventional steel}

- Three experimental 9Cr RAFM heats $(1537,1538,1539)$, together with an optimized-Gr.92 heat (C3=mod-NF616), were investigated

- composition changed to favor MX and reduce Laves phase, M23C6, and Z-phase

- Tensile strength of new TMT steels were much higher than conventional steels

- Dramatic improvement in thermal creep strength also observed
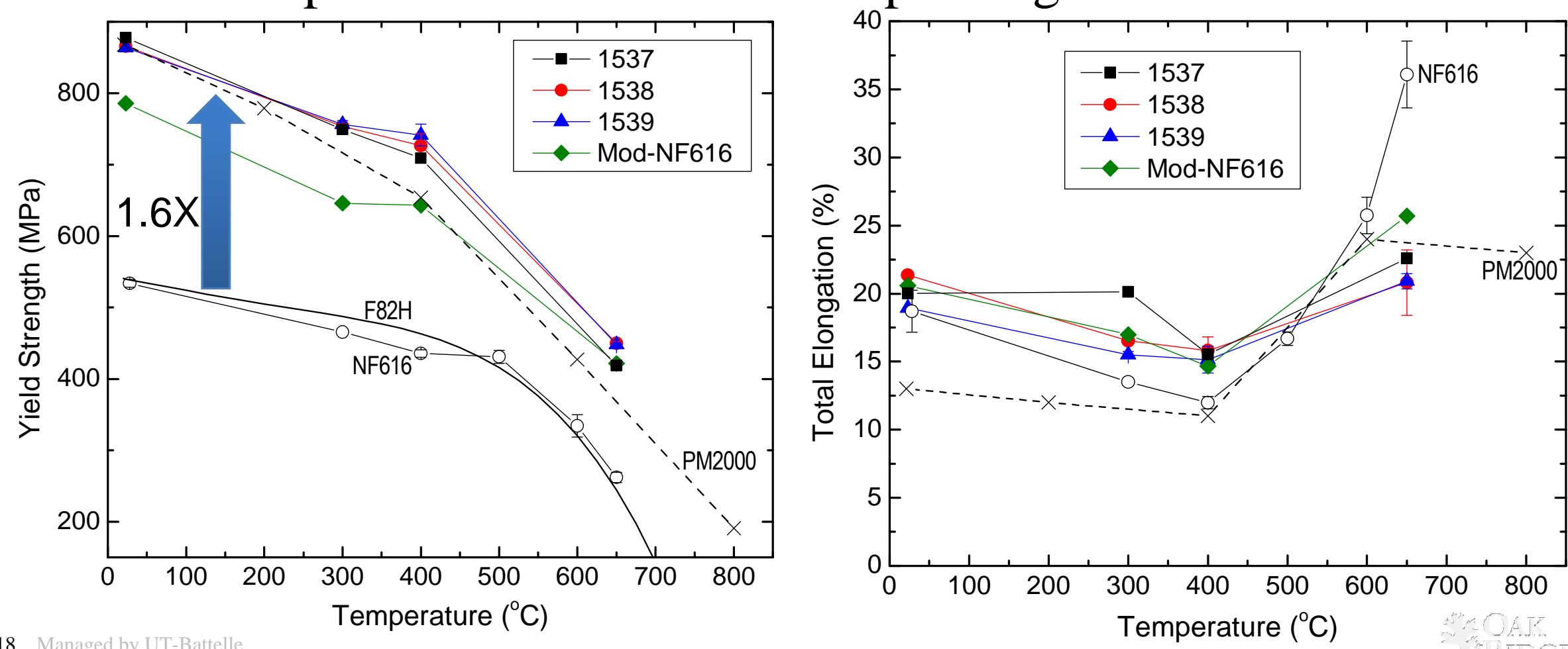


\section{Comparison of thermal creep strengths of current and compositionally modified ferritic/martensitic steels}

\section{Modified 9Cr-1Mo-New TMT}

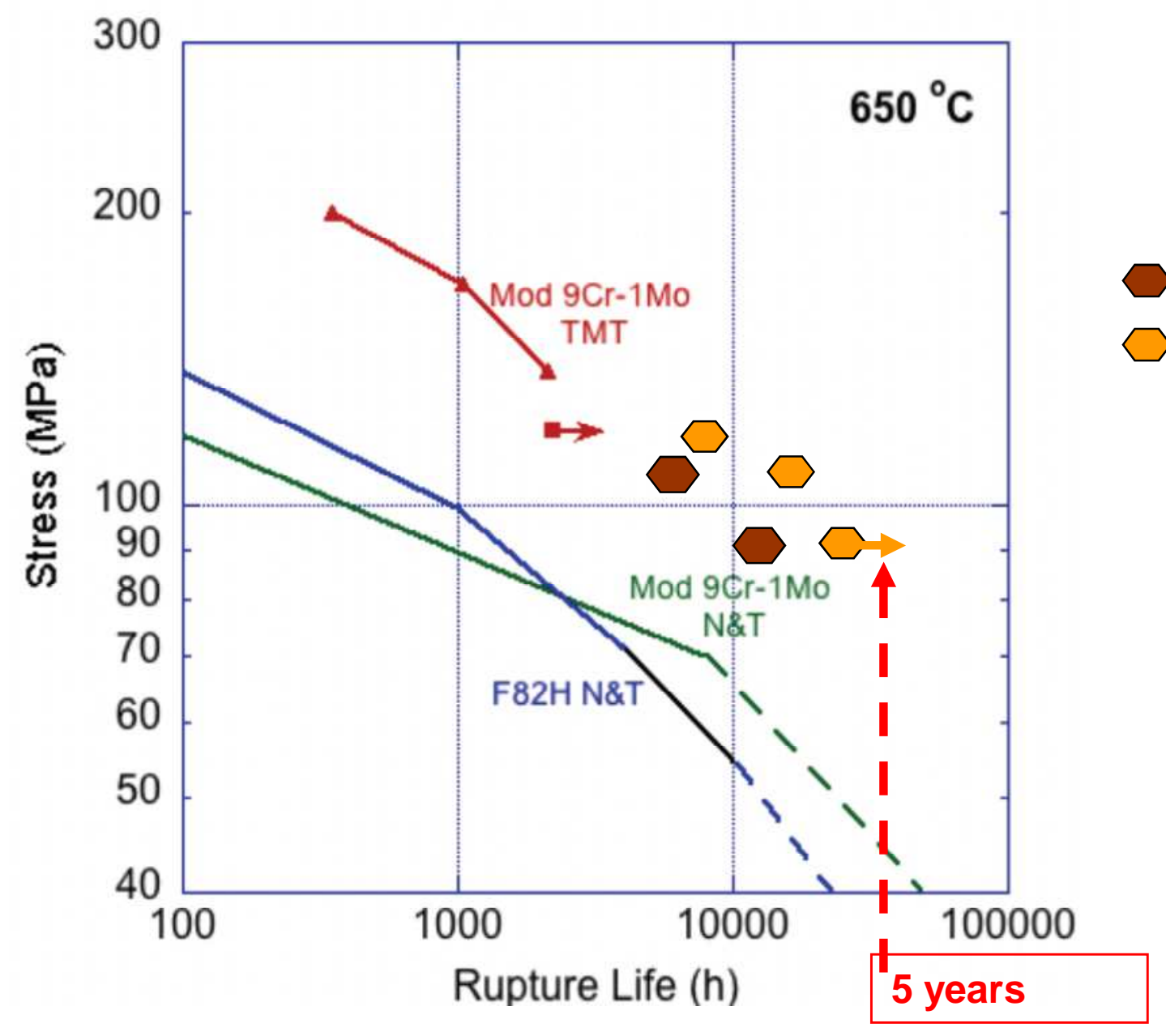

Type 92 steel with special HT

Type 92 steel with special HT $+\mathrm{C}: \mathrm{N}$ ratio

TATA Steels (UK/NL) 


\section{Creep Resistance of the Advanced 9Cr FM Steels}

- Relative to Gr92, all the advanced 9Cr FM steels showed enhanced creep resistance; Gr92-2b (TMT) and Ti-modified alloys were best

- The amount of MX-type nano-precipitates increased with thermal aging, which favored the enhancement of creep resistance
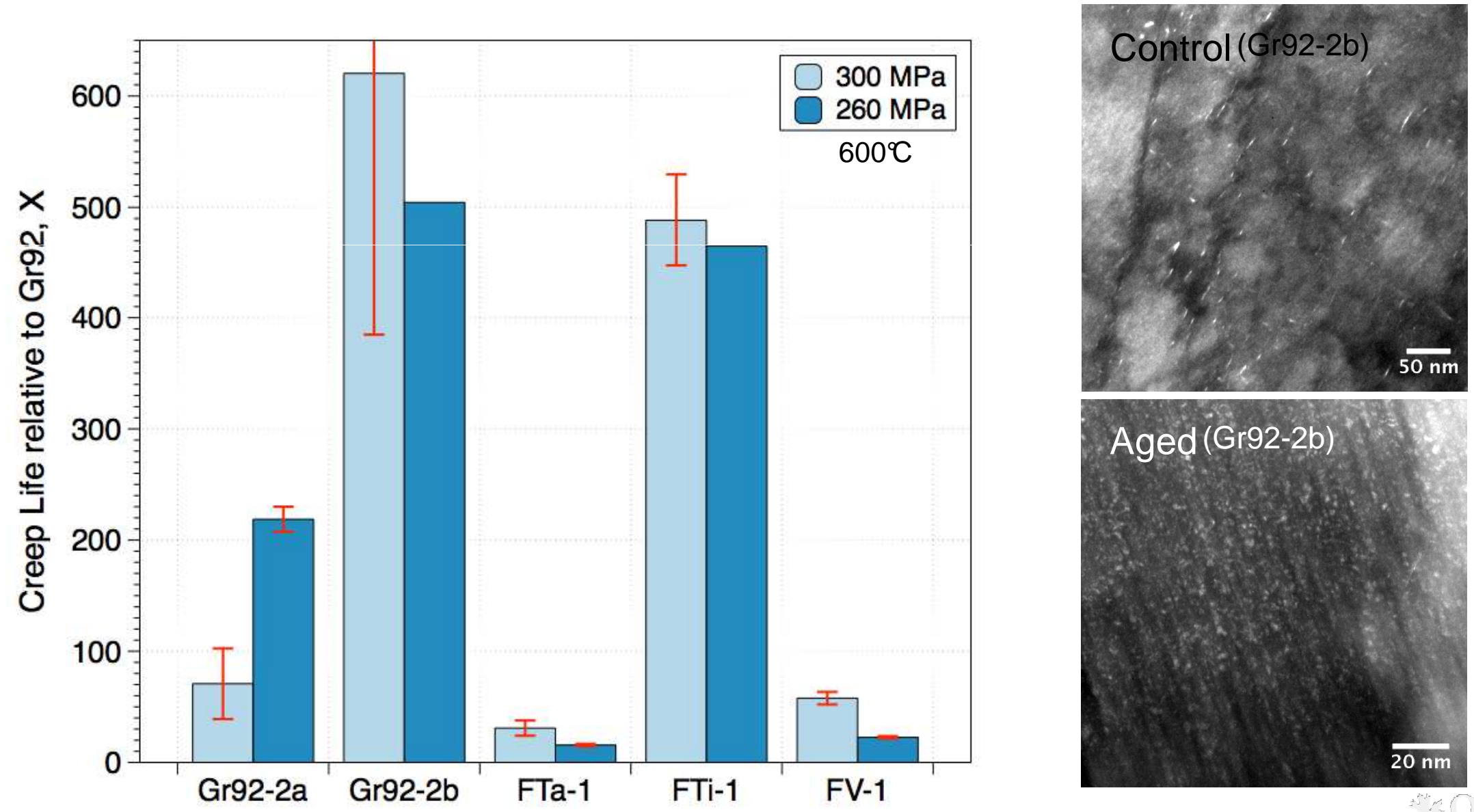

Fine-scale precipitates also provide high point defect sink strength 


\section{Comprehensive Property Assessment of Advanced Austenitic}

Alloys for Sodium-cooled Fast Reactor (SFR)

- Newly developed alloy based on HT-UPS (Fe-14Cr-16Ni base) exhibited;

- Improved weldability compared to the original HT-UPS.

- Moderate creep resistance when 10\% cold-work applied (much better than $316 \mathrm{H}$, comparable to NF709).

- Thermal stability/creep-fatigue properties of new alloys were not as good as NF709.

C Current US focus is evaluation of NF709 (Fe-22Cr-25Ni base).
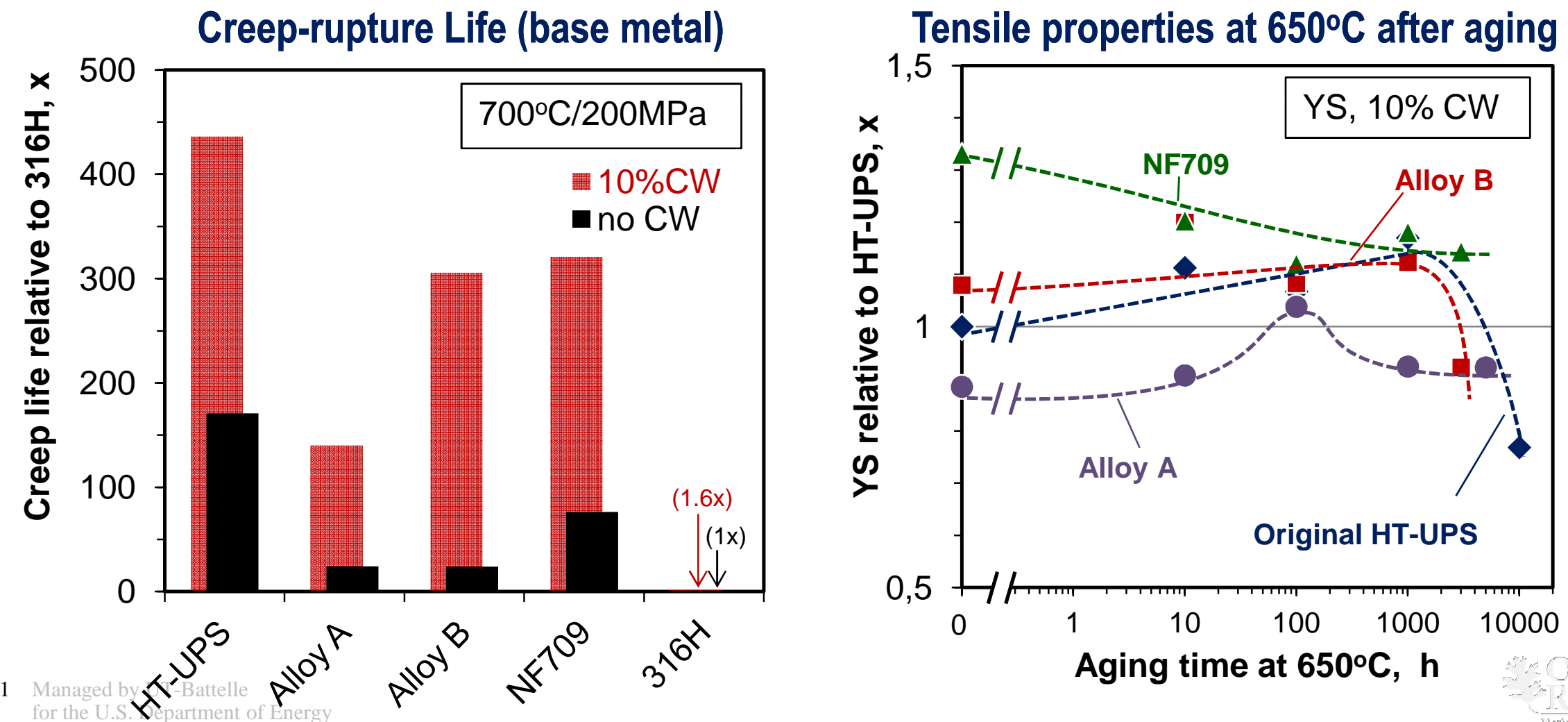


\section{Computational Thermodynamics Sped Development of Alumina-Forming Austenitic (AFA) Stainless Steels}

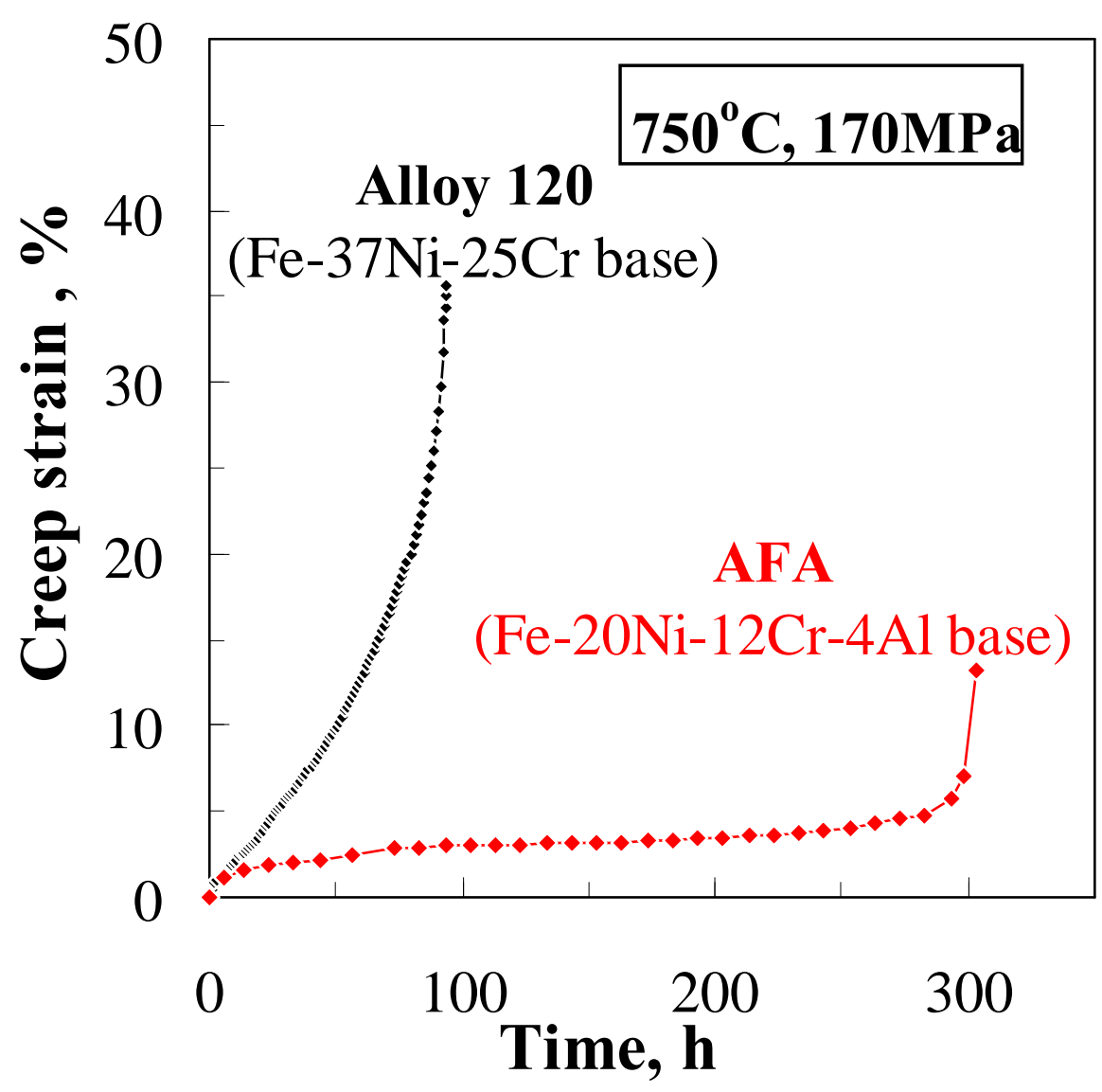

-AFA: Order of magnitude better corrosion resistance with excellent creep resistance and low alloy cost

-Initial findings published in Science, April 20, 2007

22 Man-2009 R\&D 100 Award Winner
AFA $800^{\circ} \mathrm{C} 10,000 \mathrm{~h}$ Air

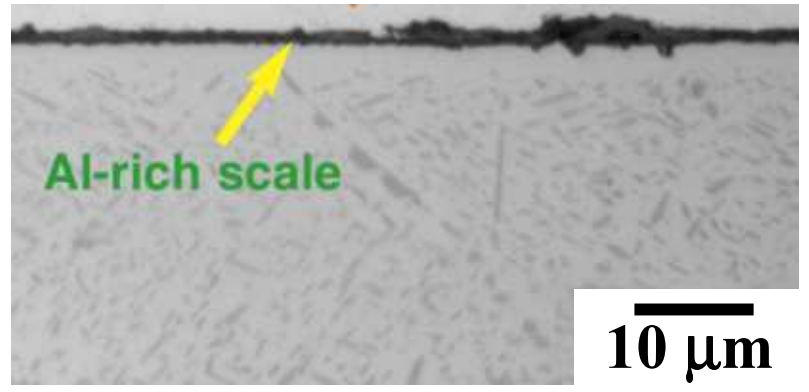

Alloy $120800^{\circ} \mathrm{C} 10,000$ h Air

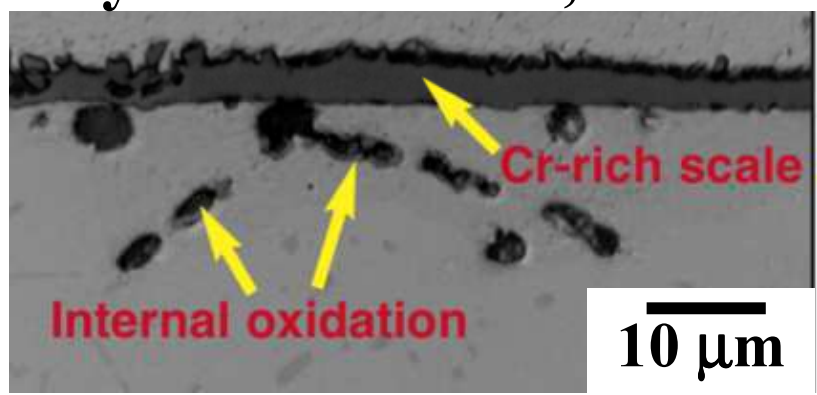

Stainless Steel $800^{\circ} \mathrm{C} 5000$ h Air

(Fe-19Cr-12Ni base)

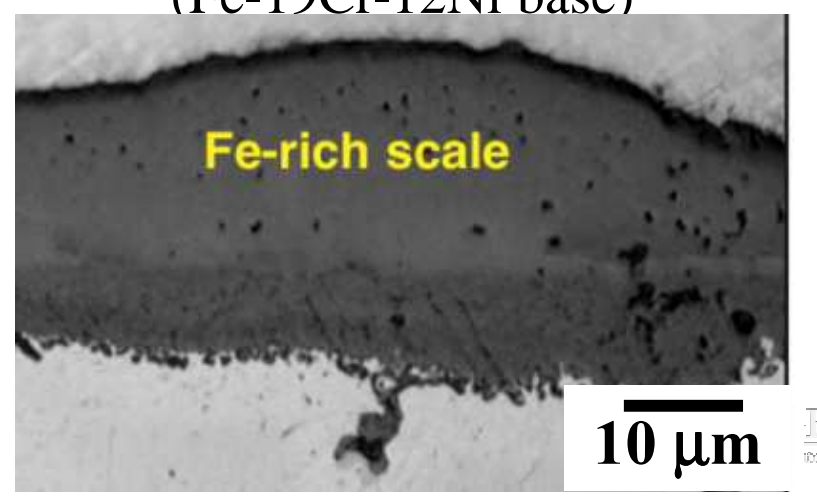




\section{Proof of Principle Established For Design of Creep}

Resistant Cast Forms of NbC-Strengthened AluminaForming Austenitic (AFA) Steel
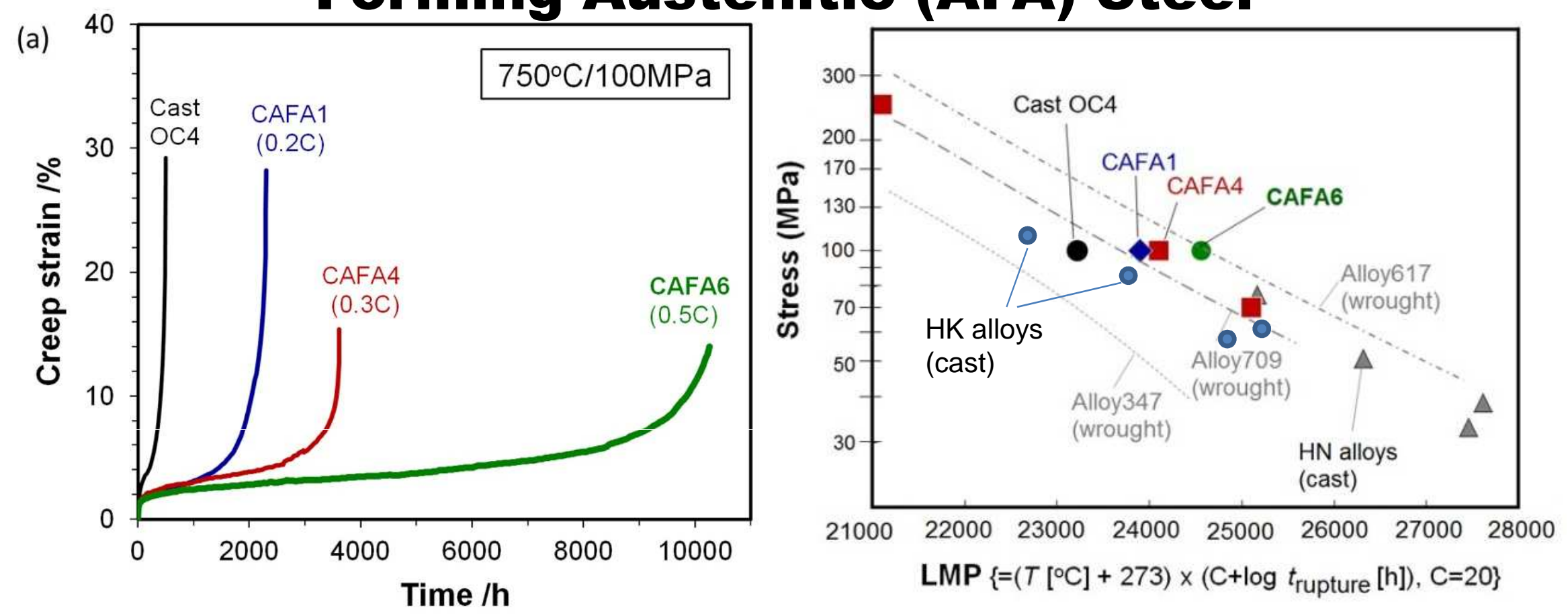

- Nb, Si, C contents co-optimized for alumina formation, creep resistance and casting (vacuum arc-cast): $\mathrm{Fe}-25 \mathrm{Ni}-14 \mathrm{Cr}-3.5 \mathrm{Al}-1 \mathrm{Nb}$ base

-high $\mathrm{C}$ castings have better creep resistance than wrought AFA -promising oxidation resistance up to $700-800^{\circ} \mathrm{C}$ (mo re data and further optimization needed)

-Next step is trial air castings of promising compositions 


\section{Low-Cost, Alumina-Forming, Fe-Base Superalloy}

\section{DARPA Funded Next Generation Alumina-Forming Austenitic (AFA)}

Stainless Steel Targeting 10x Better Creep Resistance

\section{Move from Carbide to $\gamma^{\mathbf{s}}-\mathbf{N i}_{\mathbf{3}} \mathbf{A l}$ Strengthening}

Thermodynamic Calculation of Candidate Alloy

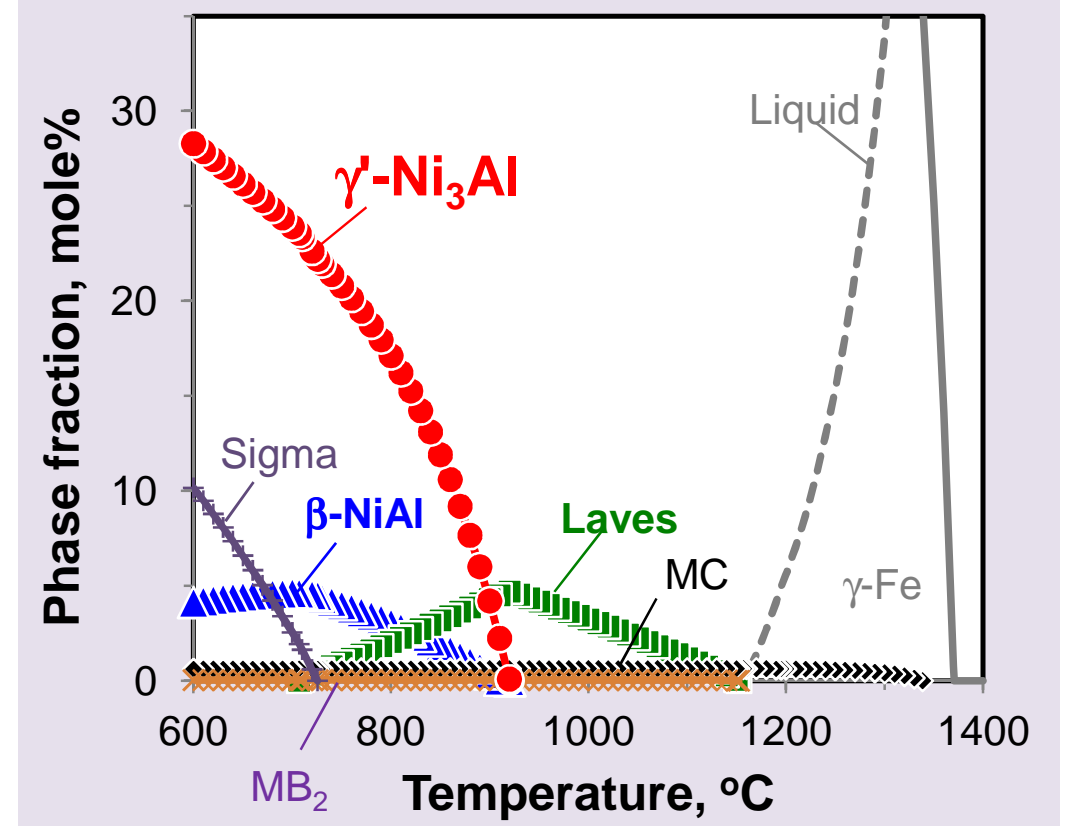

Creep-Rupture Life Behavior $\left(700^{\circ} \mathrm{C} / 170 \mathrm{MPa}\right)$

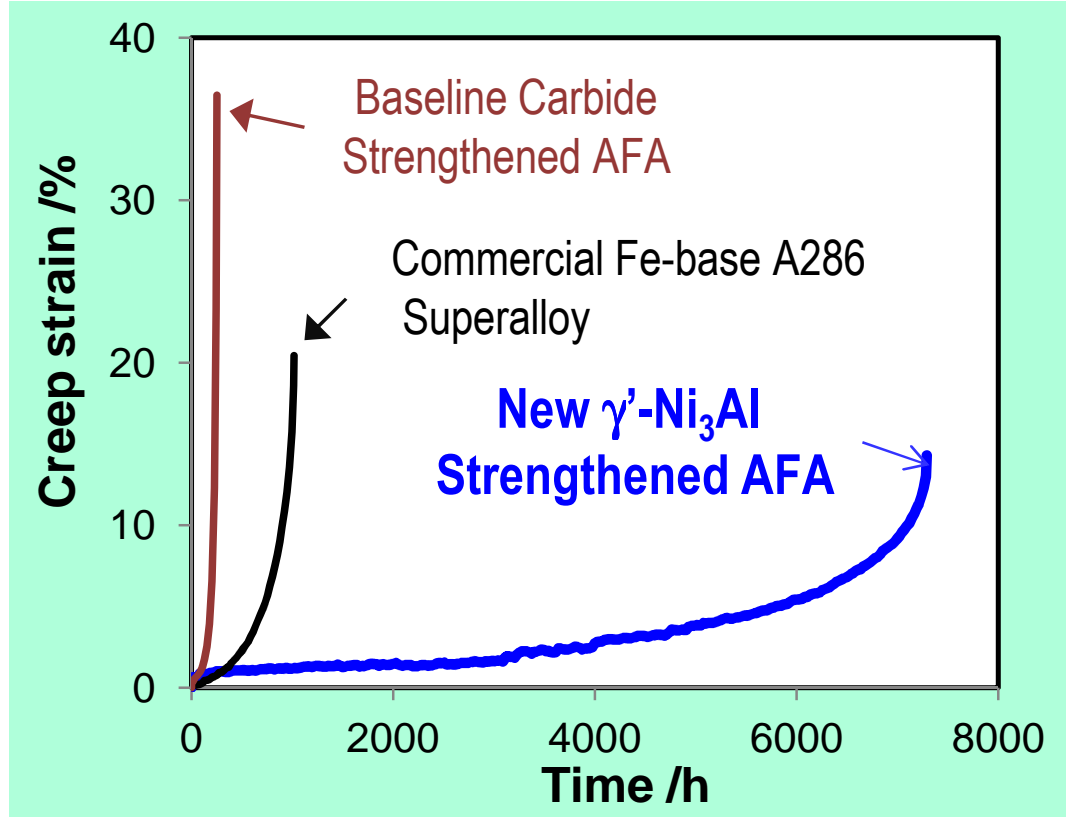

- ORNL AFA stainless steels: 2009 R\&D 100 Award, licensed to Carpenter Tech. 2011 -Superior high-temperature corrosion resistance over stainless steels $\left(\mathrm{Al}_{2} \mathrm{O}_{3}\right.$ surface $)$

-Carbide precipitates provide creep resistance comparable to advanced stainless steels

- DARPA funded discovery of $\gamma^{\prime}-\mathrm{Ni}_{3} \mathrm{Al}$ strengthened AFA w/greatly improved ereep resistance while retaining ability to form $\mathrm{Al}_{2} \mathrm{O}_{3}$ for superior corrosion resistance 


\section{New 12YWT Nanocomposited Ferritic Steel has Superior Strength compared to conventional ODS steels}

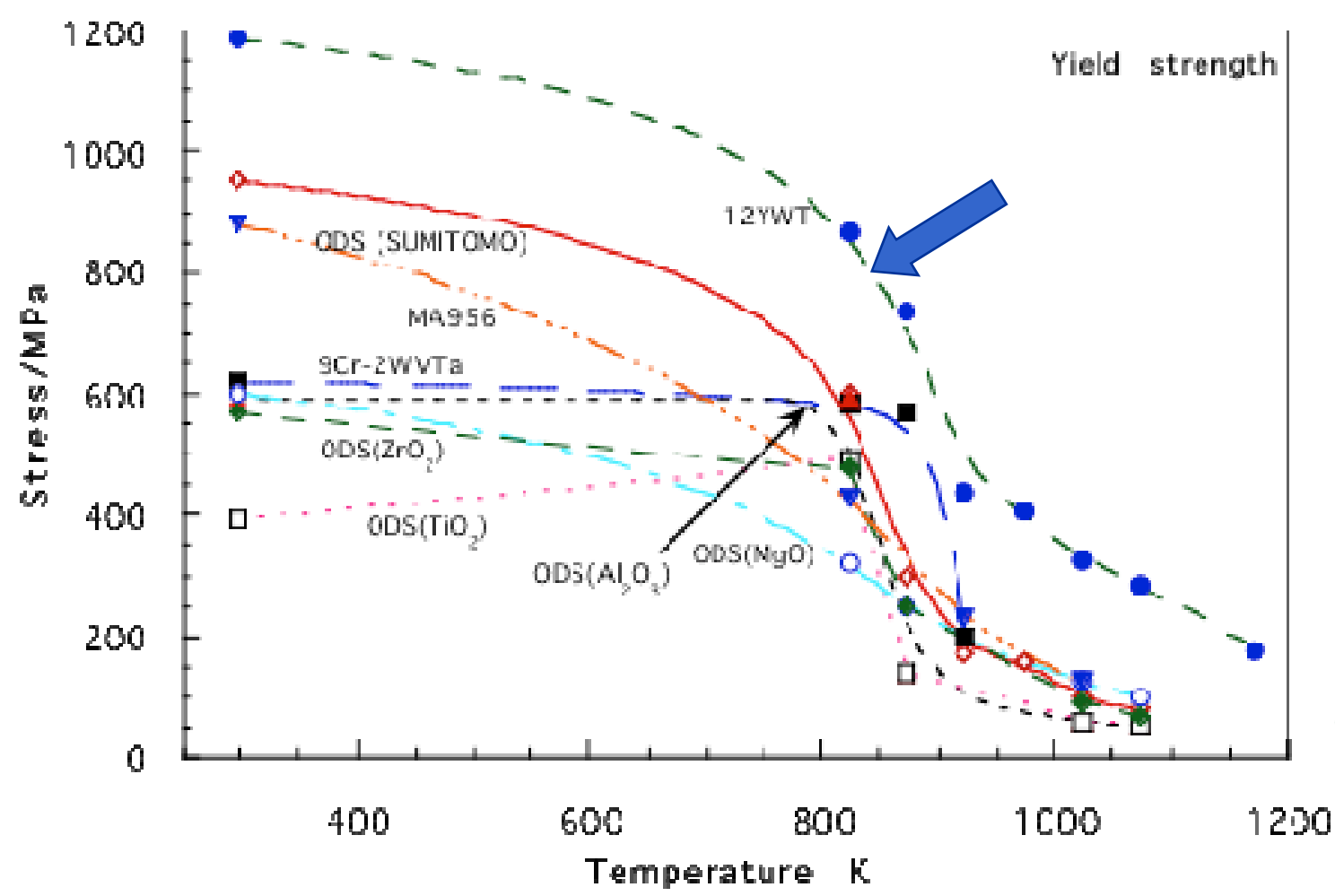

- Thermal creep time to failure is increased by several orders of magnitude at $800^{\circ} \mathrm{C}$ compared to ferritic/martensitic steels

$-2 \%$ deformation after $\sim 2$ years at $800^{\circ} \mathrm{C}, 140 \mathrm{MPa}$

- Potential for increasing the upper operating temperature of iron based alloys by $\sim 200^{\circ} \mathrm{C}$

- Acceptable fracture toughness near room temperature

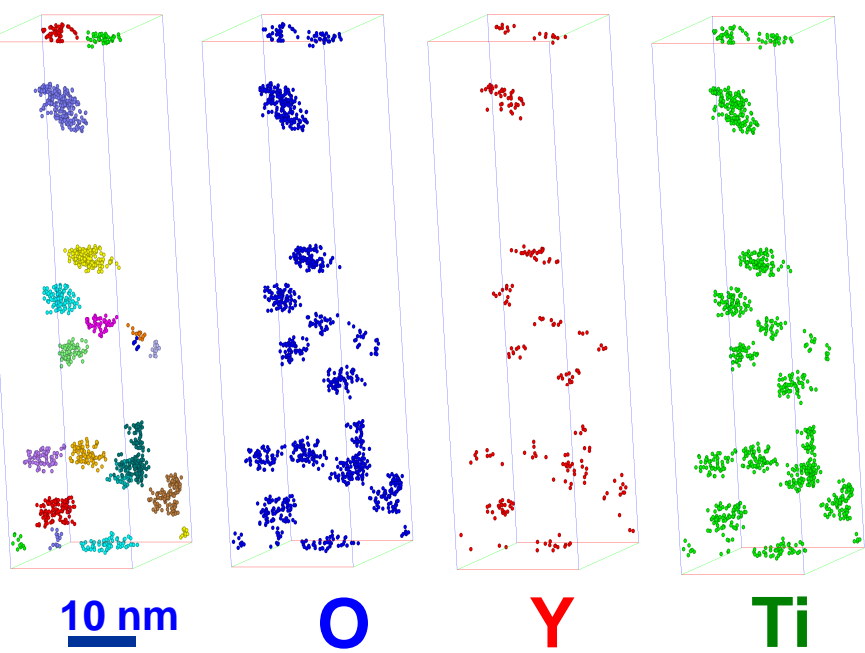

- Atom Probe reveals nanoscale clusters to be source of superior strength

- Enriched in O(24 at\%), Ti(20\%), Y (9\%)

- Size : $r_{g}=2.0 \pm 0.8 \mathrm{~nm}$

- Number Density : $\mathrm{n}_{\mathrm{v}}=1.4 \times 10^{24} / \mathrm{m}^{3}$

- Original $\mathrm{Y}_{2} \mathrm{O}_{3}$ particles convert to thermally stable nanoscale $(\mathrm{Ti}, \mathrm{Y}, \mathrm{Cr}, \mathrm{O})$ particles during processing

- Nanoclusters not present in ODS Fe-13Cr + $0.25 \mathrm{Y}_{2} \mathrm{O}_{3}$ alloy 


\section{Recent research suggests high-strength steels that retain}

high-toughness are achievable

- Generally obtained by producing high density of nanoscale precipitates and elimination of coarse particles that serve as stress concentrator points

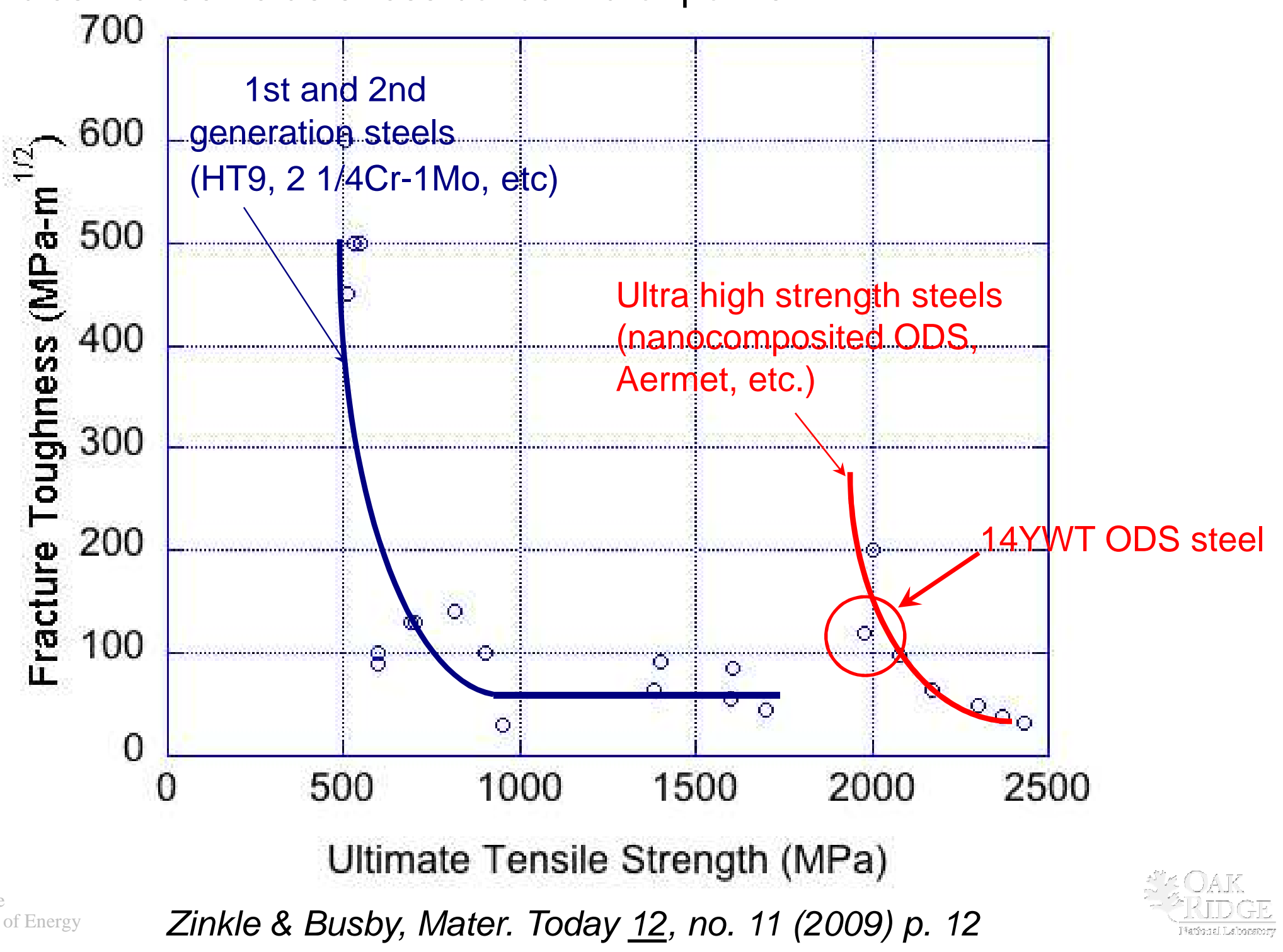




\section{The magnitude of low temperature radiation embrittlement can be suppressed by using a very high concentration of radiation defect sinks}

$300^{\circ} \mathrm{C}$, 1.5dpa: Minimal DBTT shift in $14 \mathrm{YWT}$, vs. $85^{\circ} \mathrm{C}$ shift for Eurofer ODS steel
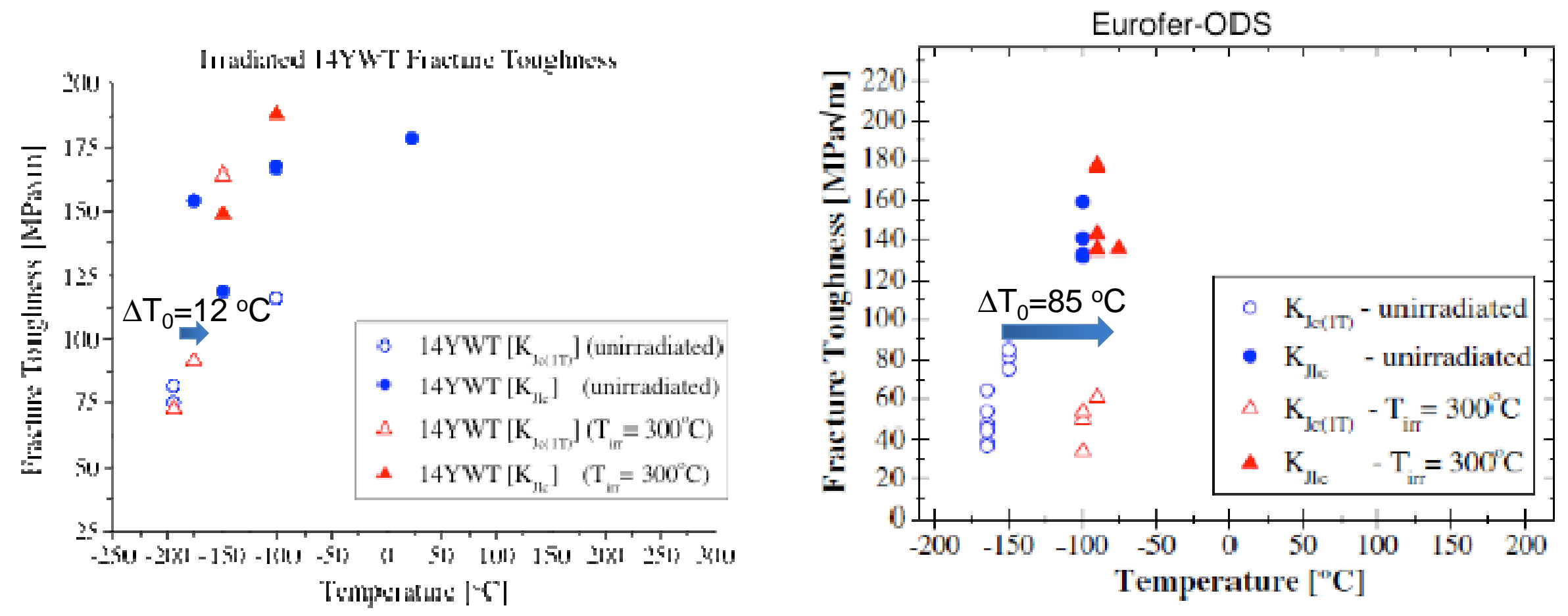


\section{Advanced Manufacturing Techniques offer the potential to enable rapid fabrication of complex geometries}

Examples of additive manufacturing technologies

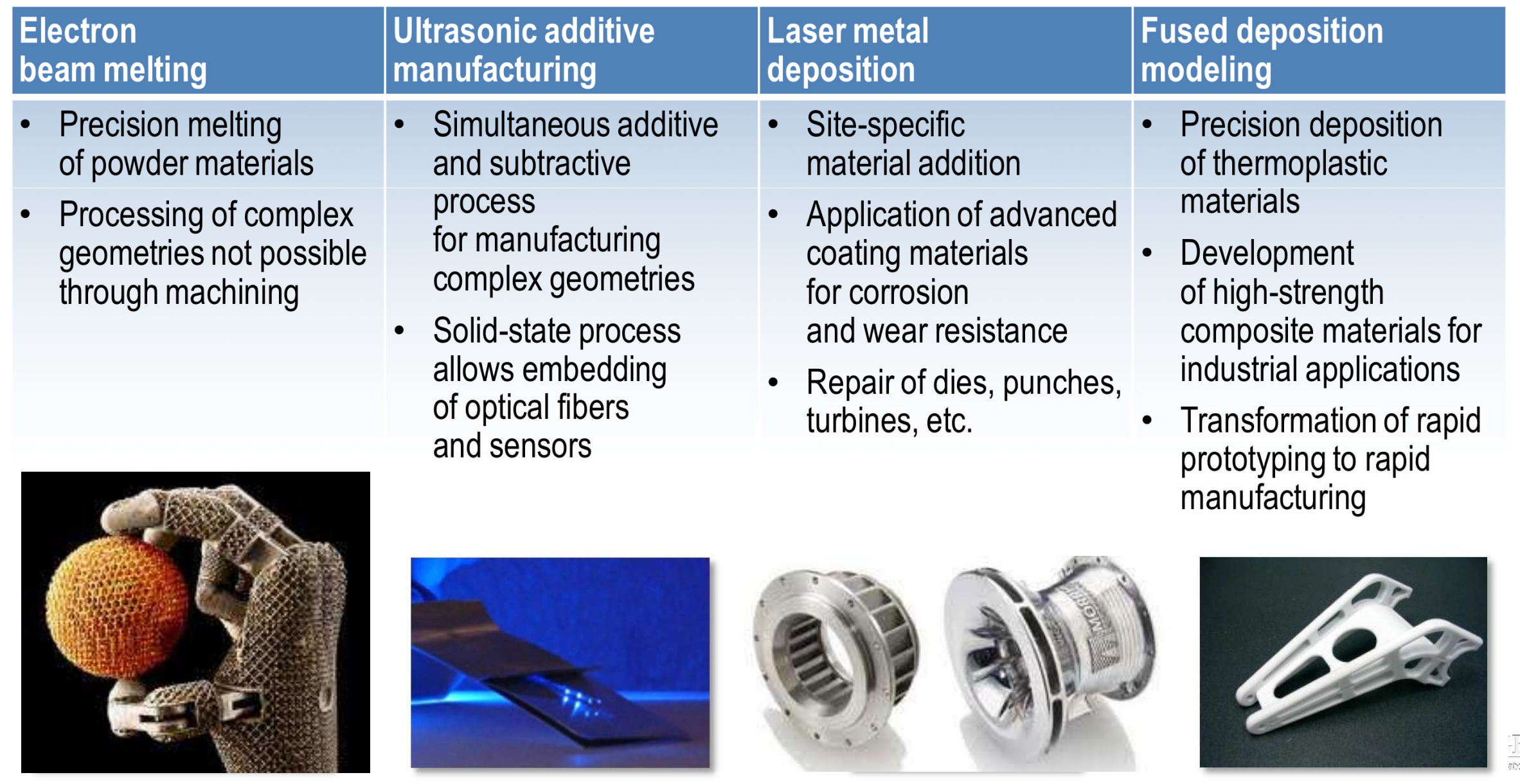




\section{Overview of $\mathrm{SiC} / \mathrm{SiC}$ composites for nuclear energy}

- Fission reactor irradiation stability up to 40 dpa confirmed for currentgeneration $\mathrm{SiC} / \mathrm{SiC}$ composites

- Outstanding issues include improvements in leak-tightness and fabrication (complexity and cost) and development of structural design criteria

Data from recent US/J HFIR study
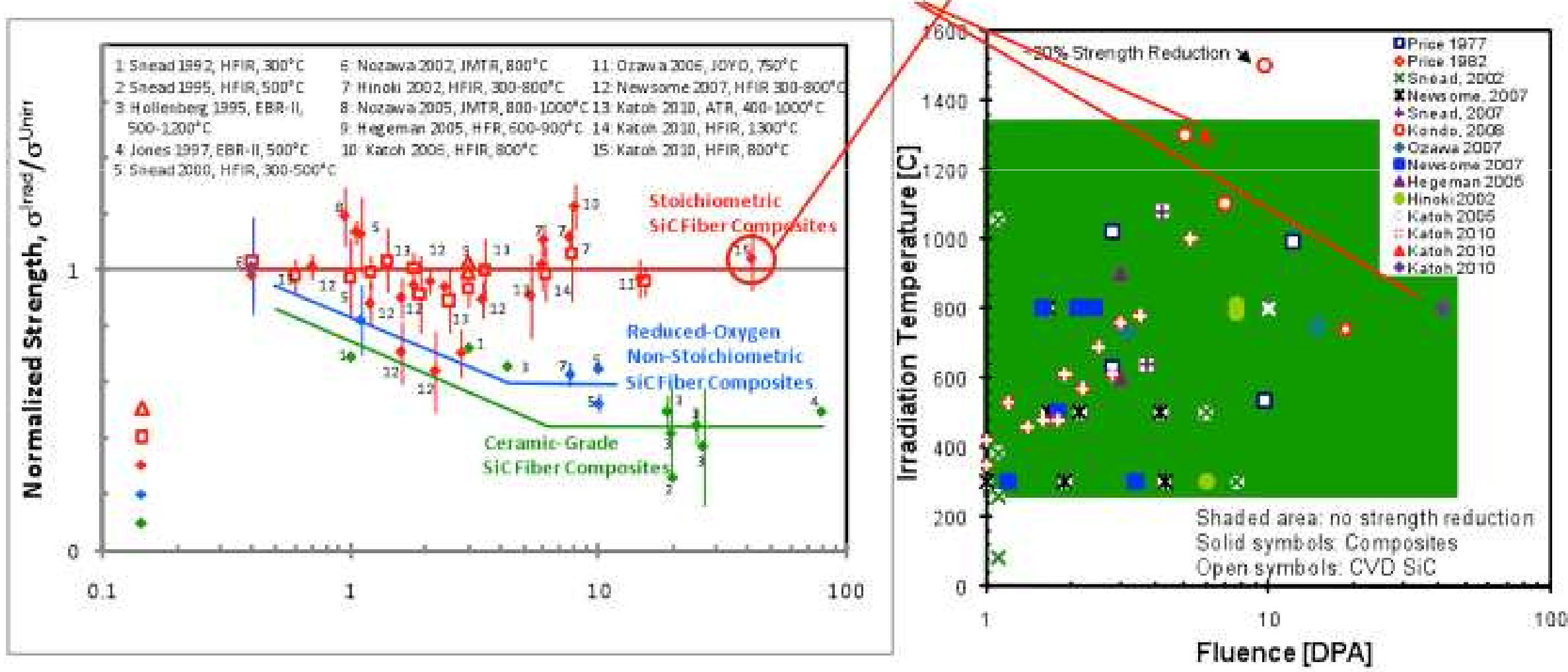


\section{Status and recent highlights: $\mathrm{SiC} / \mathrm{SiC}$ composites}

- Fission reactor irradiation stability up to $70 \mathrm{dpa}$ at 500 and $800^{\circ} \mathrm{C}$

- Further improvements in development of stoichiometric SiC fibers may be needed for higher dose applications

- Scoping low dose irradiation studies on $\mathrm{SiC}$ joints found no degradation for several joining technologies

Hi-Nicalon Type S fiber reinforced CVI SiC

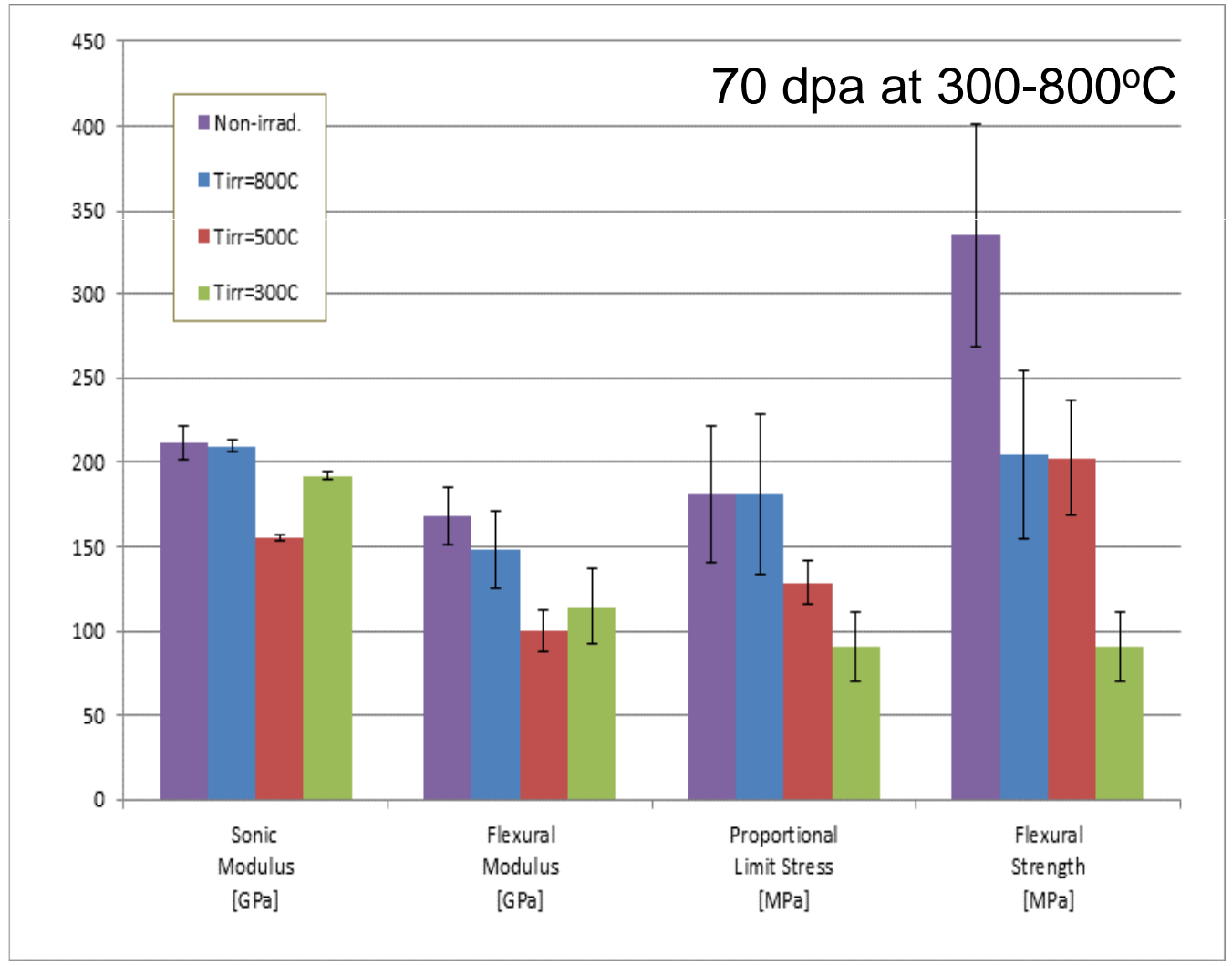

30 Manage $Y$. Katoh et al., ORNL/TM-2012/459 (2012)
for the U. Kato room temperature torsional shear strength of $\mathrm{SiC} / \mathrm{SiC}$ composite joints

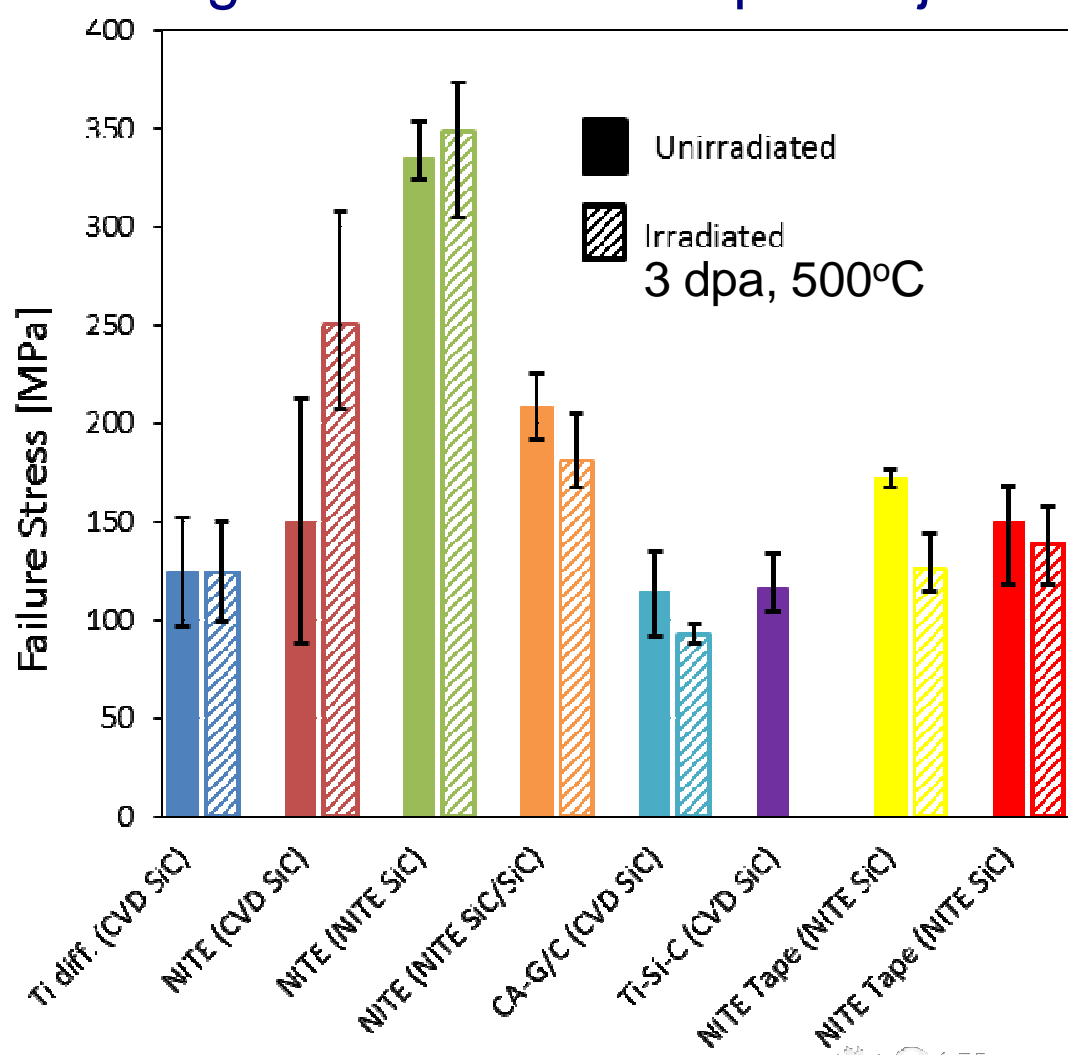

Y. Katoh et al., NuMat, Osaka, Japan (2012) 


\section{US Reactor Fuel Performance: Higher burnup with fewer failures}
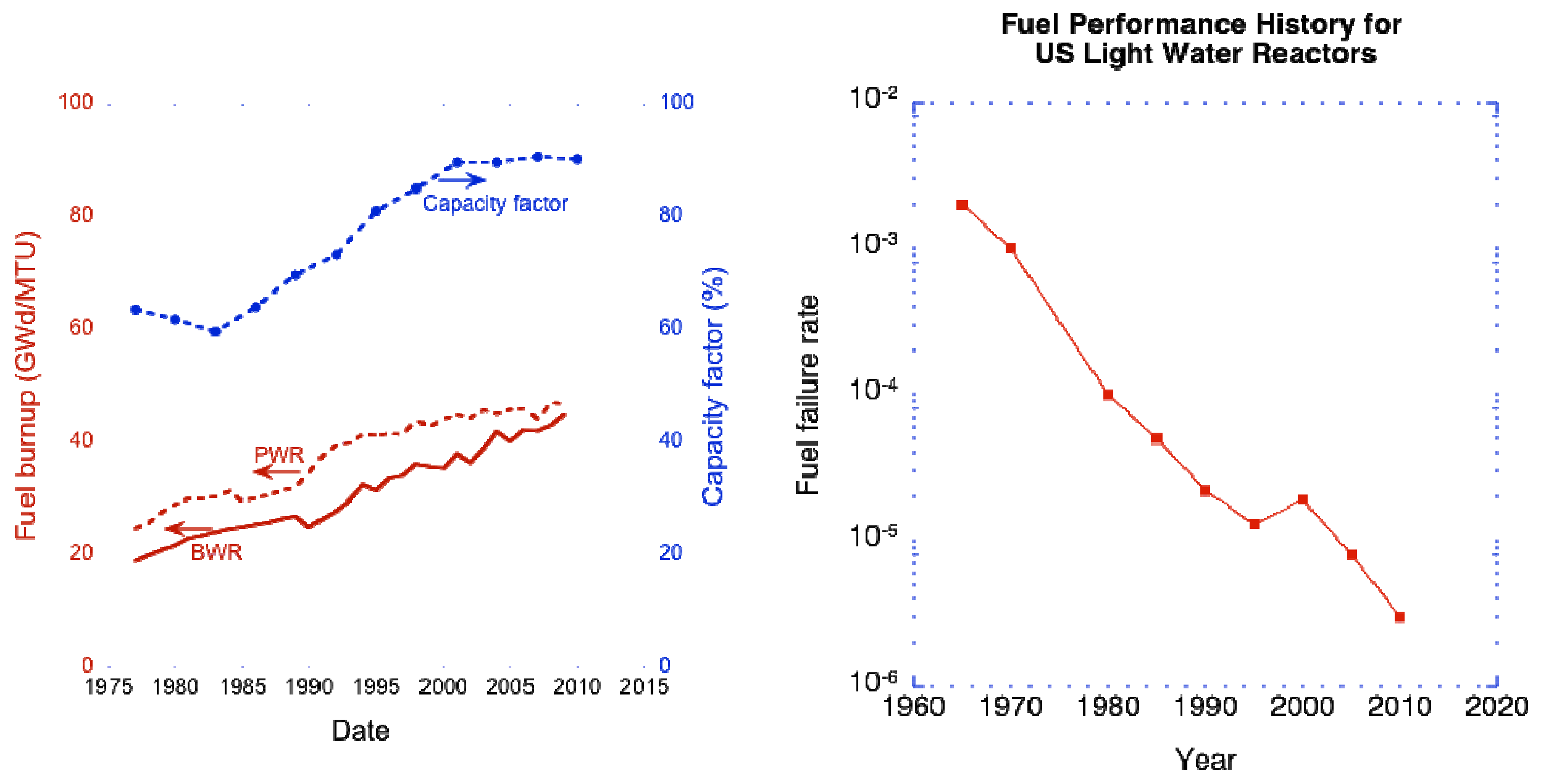

31 Managed by UT-Batelle Zinkle \& Was, Acta Mater. $\underline{61}$, in press (diamond jubilee special issue, 2013) 


\section{There are three major potential strategies for accident tolerance}

Suppressed Reaction Kinetics with Steam

to minimize enthalpy input and hydrogen

generation

-Oxidation rate

-Heat of oxidation

\section{Improved Fuel Properties}

-Lower operating temperatures

-Clad internal oxidation

-Fuel relocation / dispersion

-Enhanced retention of fission products

-Fuel melting safety margin

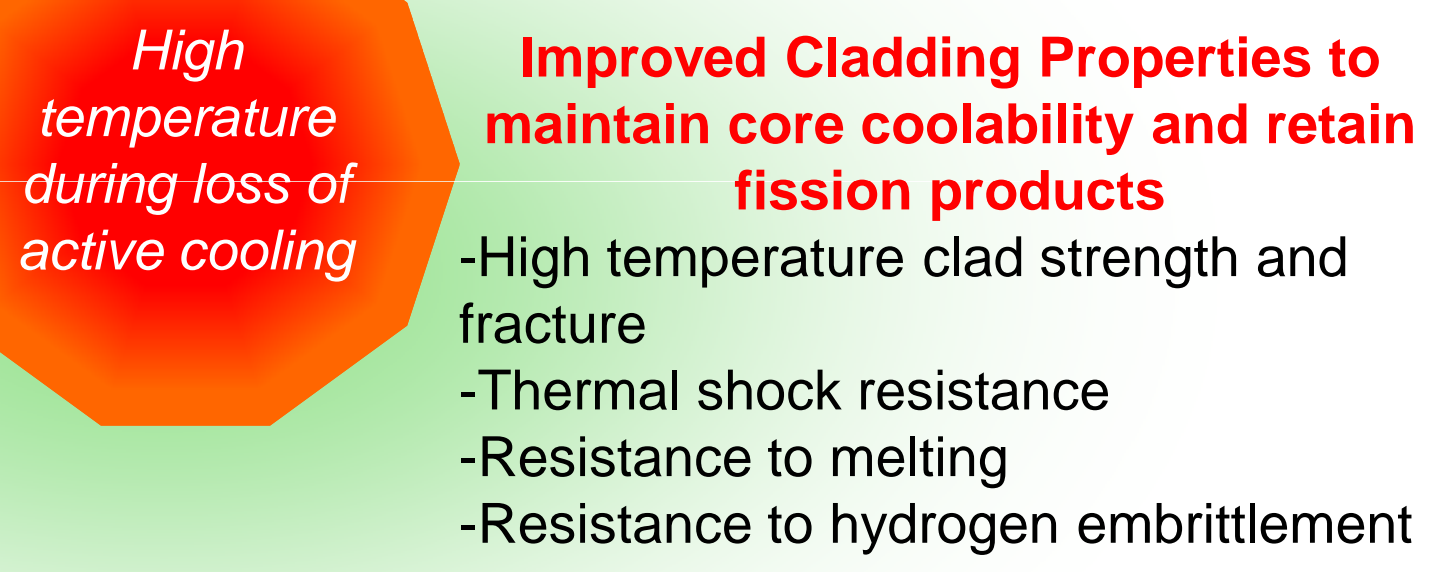

High temperature during loss of active cooling

Improved Cladding Properties to maintain core coolability and retain fission products

-High temperature clad strength and fracture -Thermal shock resistance -Resistance to melting -Resistance to hydrogen embrittlement

- potential options for fuel cladding include:

- Oxidation-resistant alloy cladding (e.g., steels)

- Oxidation-resistant coatings on $\mathrm{Zr}$ alloy cladding

- Ceramic matrix composite cladding 


\section{A Loss of Coolant Accident (LOCA) such as what occurred at the Fukushima Dai-ichi site is the most severe postulated safety case for nuclear reactors}

- Loss of offsite power due to tsunami $1 \mathrm{~h}$ after reactor scram

- On-site diesel generators and battery power was lost immediately (unit 1) or after a few days (units $2 \& 3$ )

- Inability to remove MWs of residual heat led to temperature increase in the core

- At high temperatures, the $\mathrm{Zr}$ alloy cladding oxidation increases and becomes the dominant source of heat (with $\mathrm{H}_{2}$ gas as a byproduct)
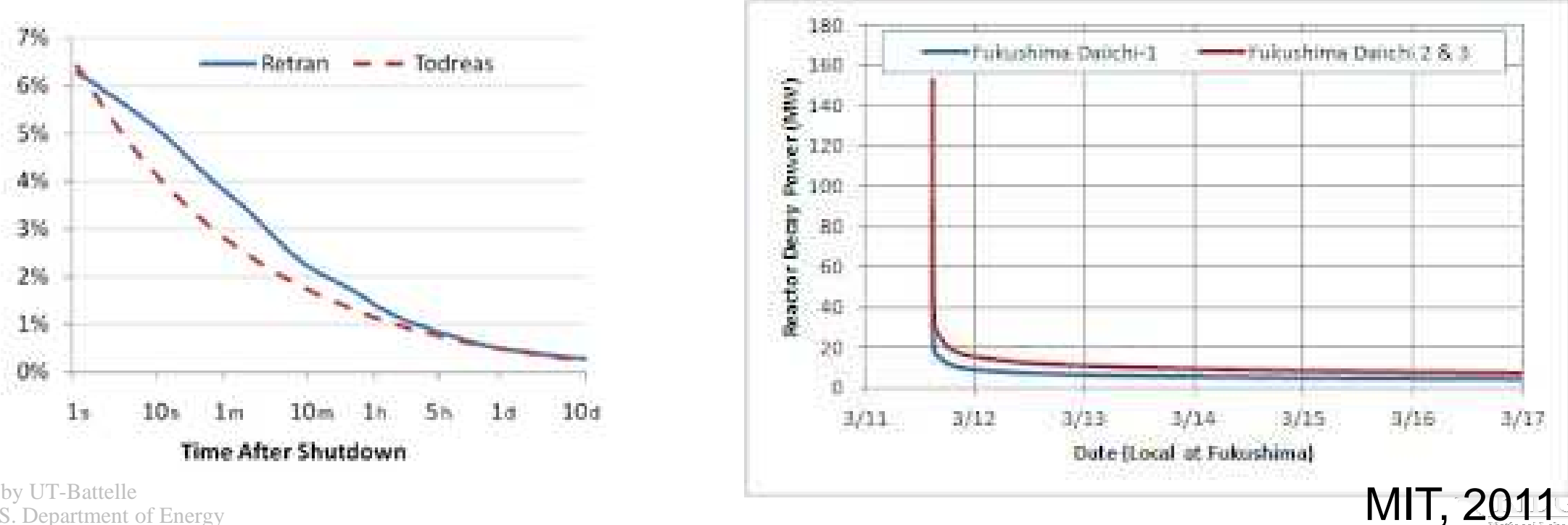


\section{Oxidation behavior of zircaloy cladding under}

\section{LOCA conditions}

Cladding temperature evolution $\left(600^{\circ} \mathrm{C}\right.$ steam) for different cooling periods

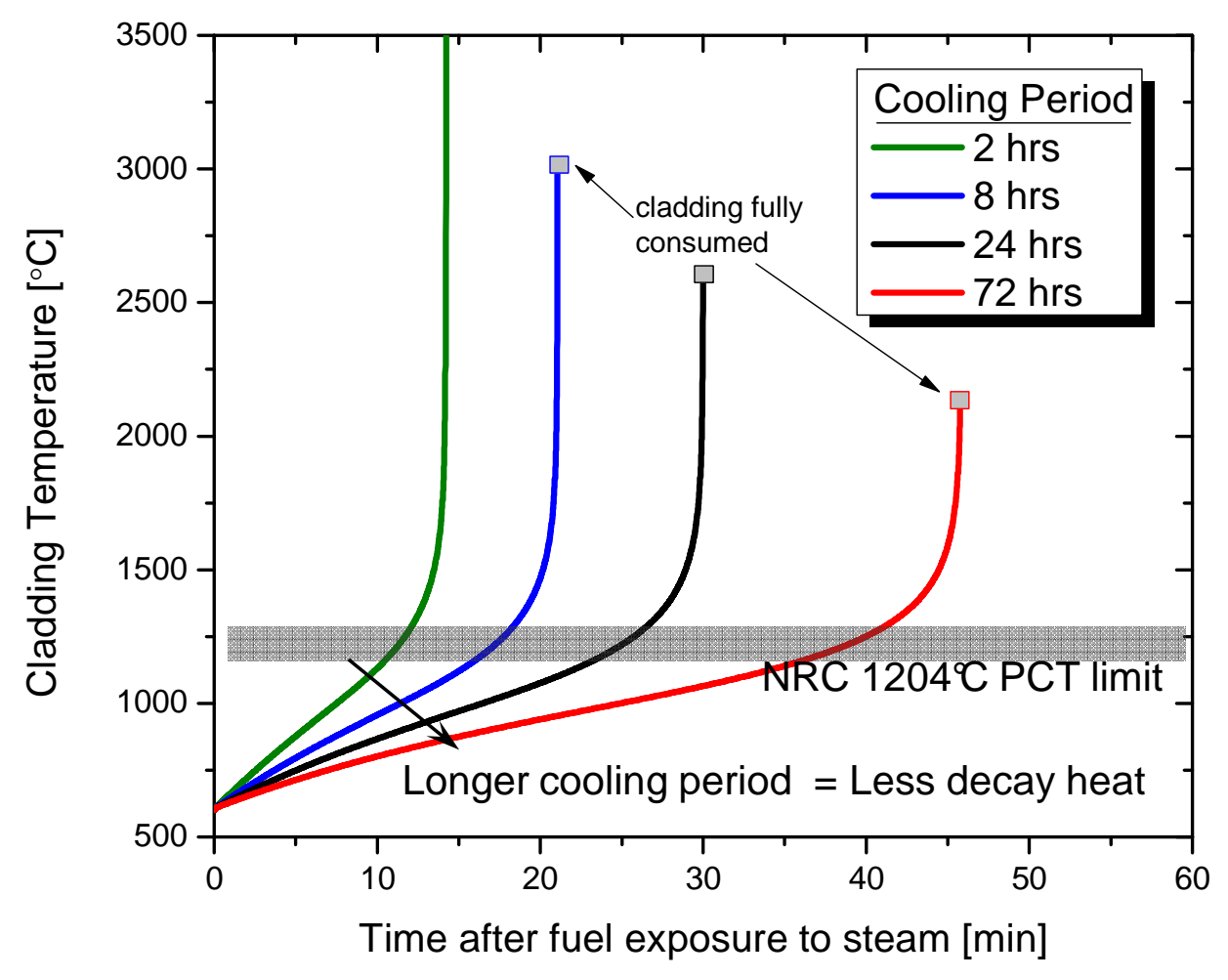

K. Terrani, L. Snead, S. Zinkle et al., to be published
Cladding heat evolution due to oxidation $\left(600^{\circ} \mathrm{C}\right.$ steam) after $8 \mathrm{~h}$ cooling period

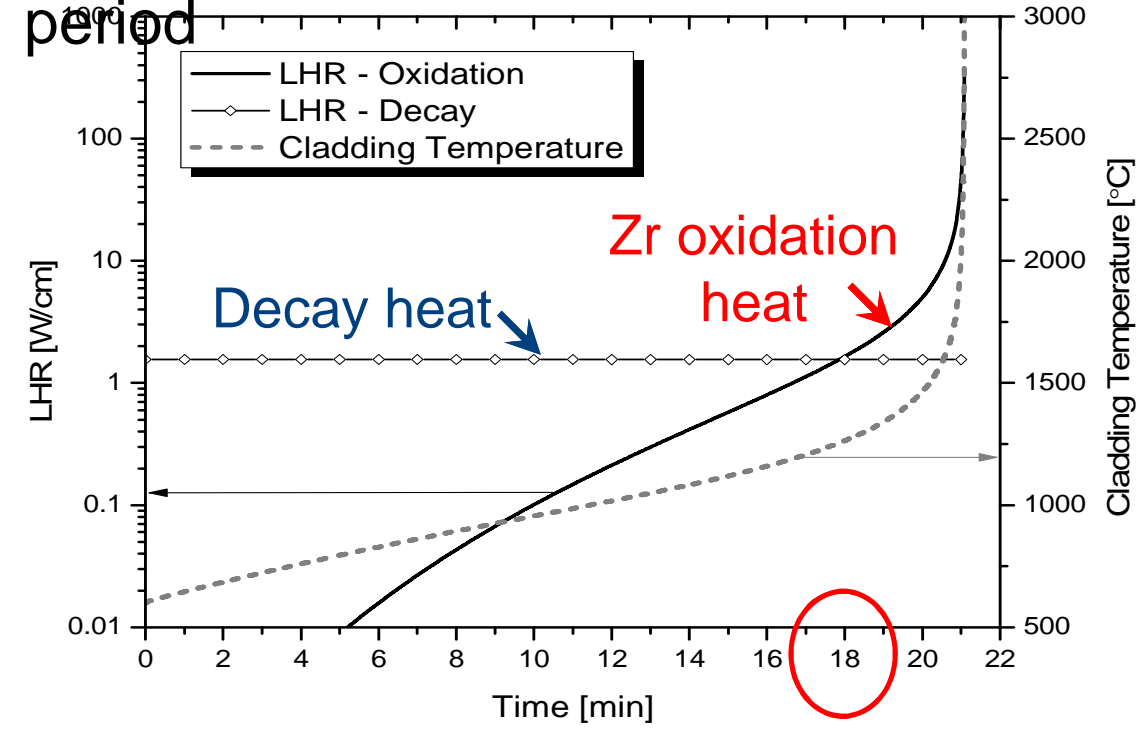

Cladding temperature evolution due to oxidation heating after $24 \mathrm{~h}$ cooling period

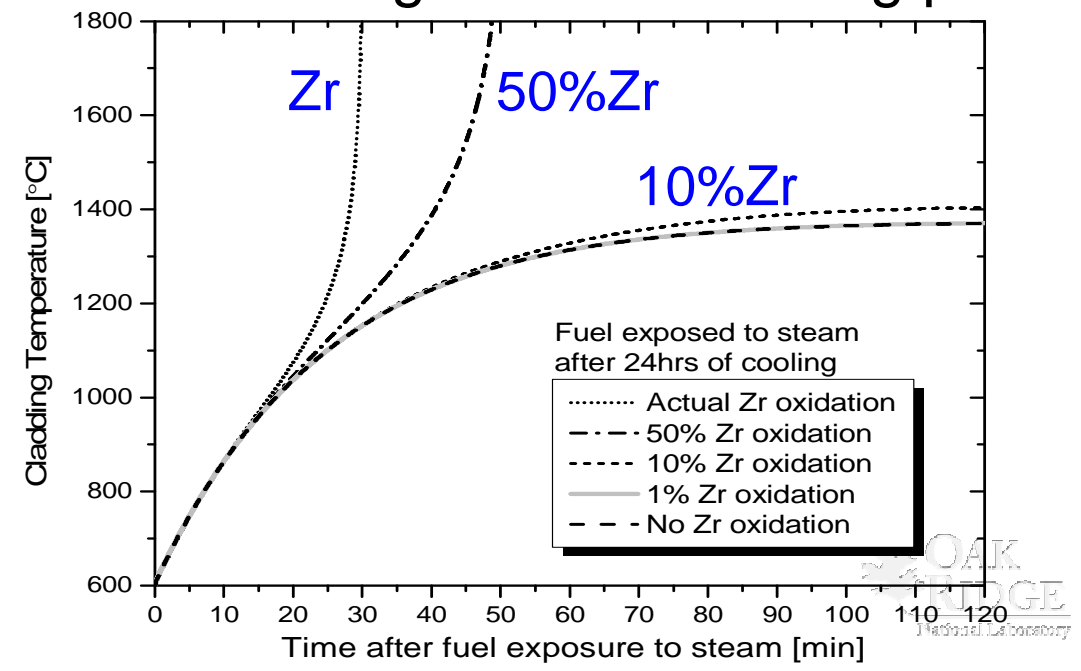




\section{Thermal creep strength of some candidate cladding materials}

Comparison of $100 \mathrm{~h}$ creep rupture strengths of candidate fuel cladding materials
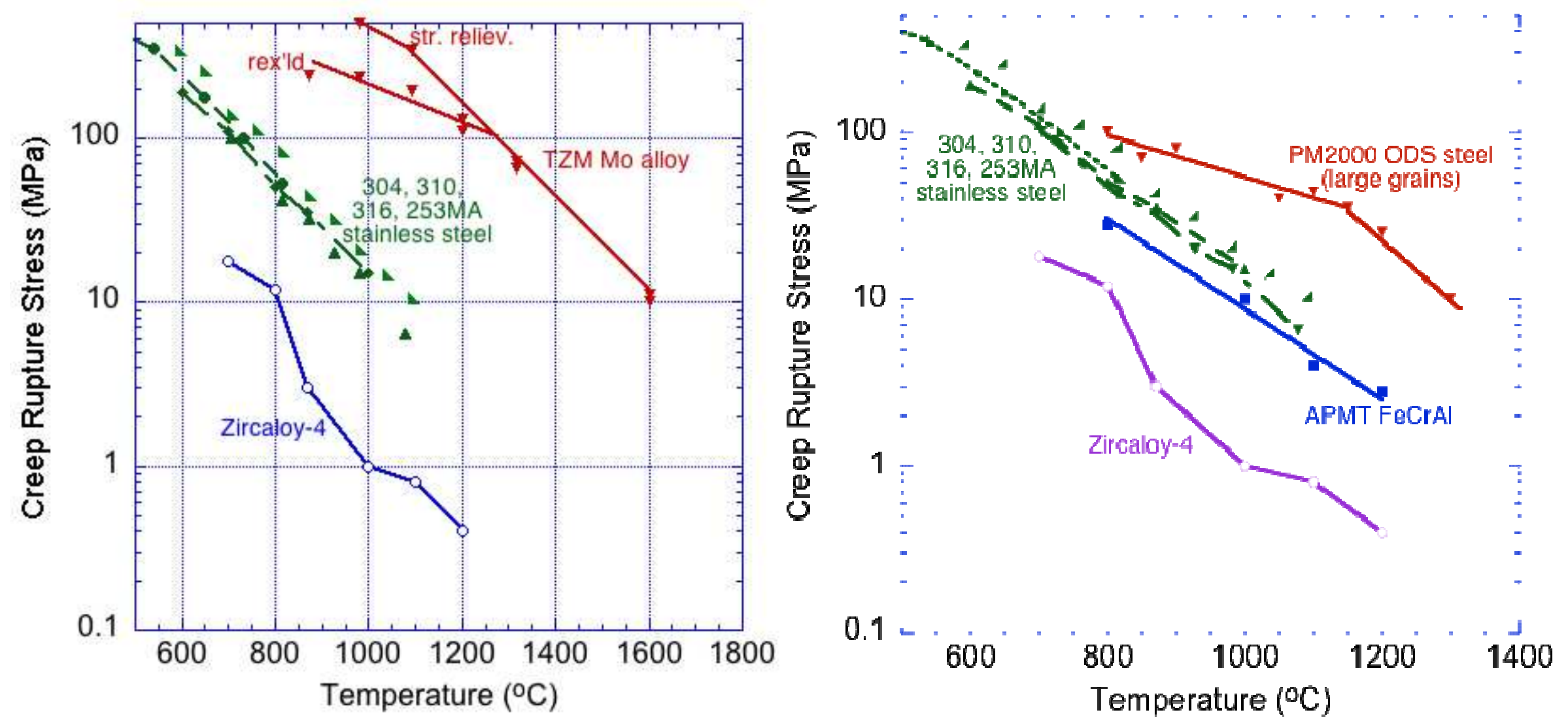

- Mo alloys and steels (and SiC/SiC, not plotted) offer improved high temperature strength 


\section{High-Pressure Steam Oxidation Tests: Comparison of the Extent of Steam Reaction}

Various materials exposed to pure steam for 8 hours (various flow rates and pressures):

- Zircaloy: Pawel-Cathcart and Moalem-Olander data

- 317 Stainless Steel: ORNL high-pressure tests; thickness loss data

- $\quad$ NITE and CVD SiC: ORNL high-pressure tests; thickness loss data

- 310 Stainless Steel: ORNL high-pressure tests; mass gain data converted to thickness loss

- FeCrAl Ferritic Steel: ORNL high-pressure tests; mass gain data converted to thickness loss

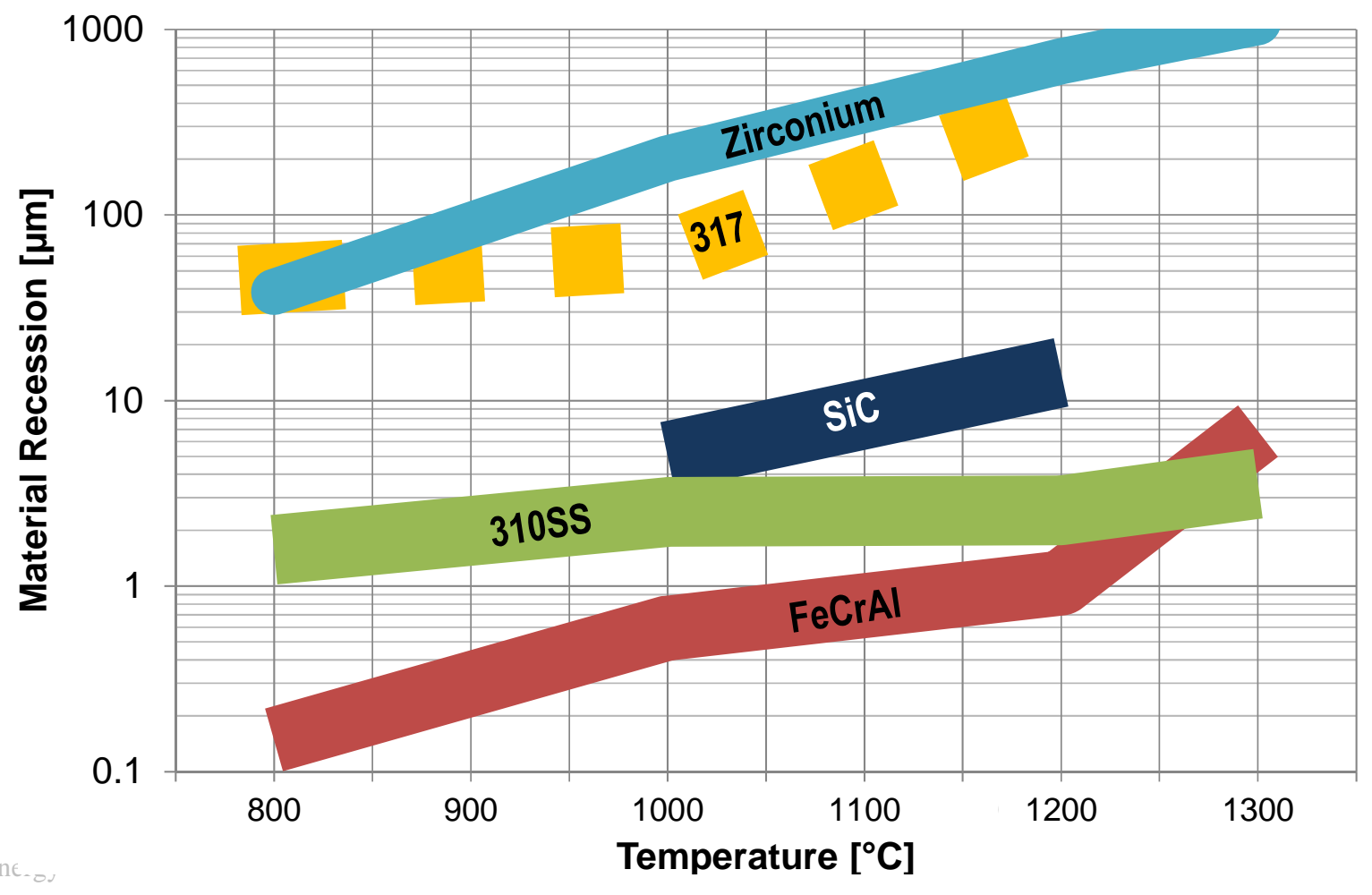




\section{Comparison of Advanced Fe-based Alloys Steam Oxidation}

Rate with Zr Alloys

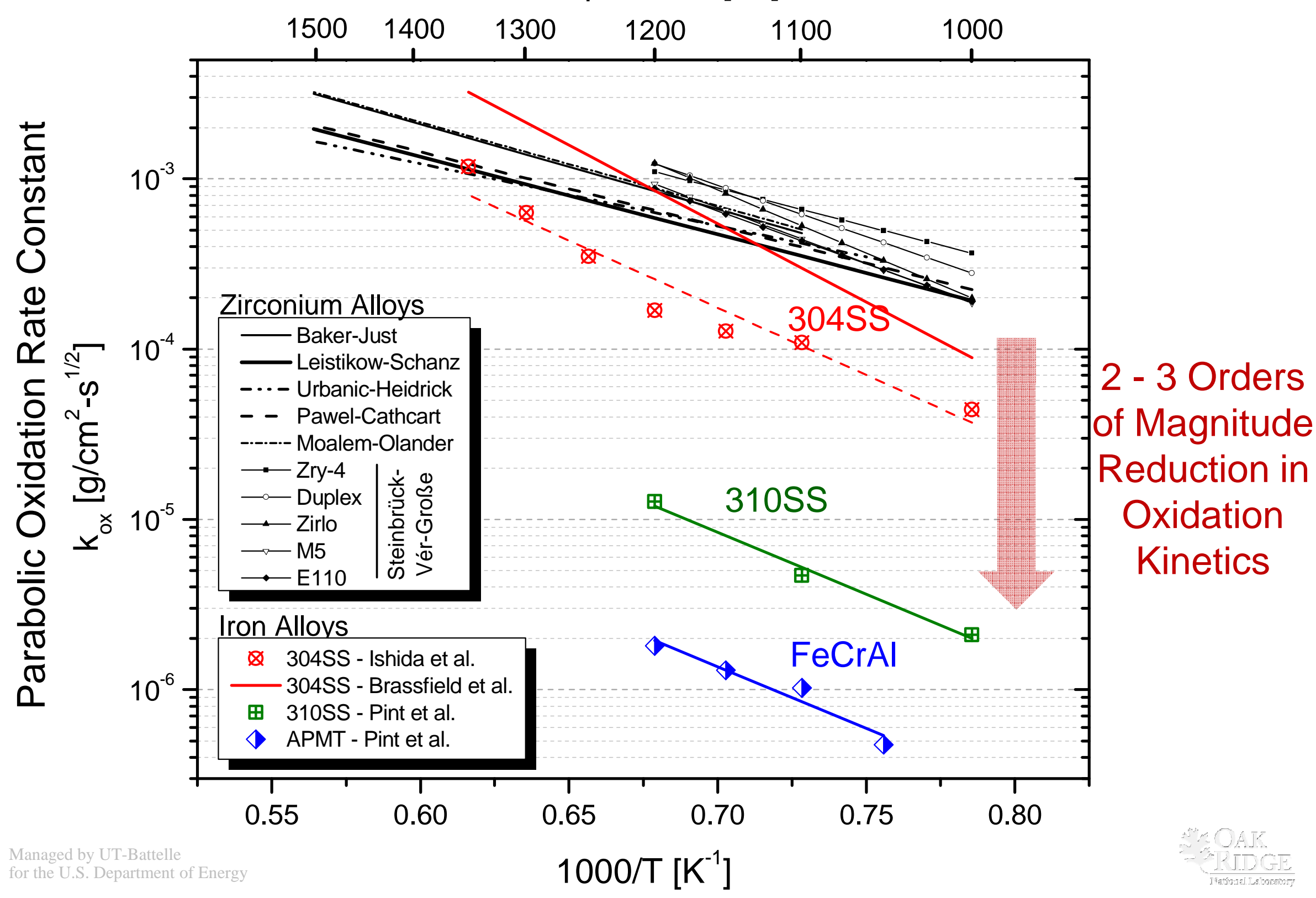




\section{Neutronics and Economics of Steel Clad}

Two strategies to make up for higher neutron absorption in the steel cladding and maintain identical cycle lengths to $\mathrm{Zr}$ clad:

- Reduce clad thickness (steel is stronger and more oxidation resistant)

- Increase ${ }^{235} \mathrm{U}$ enrichment

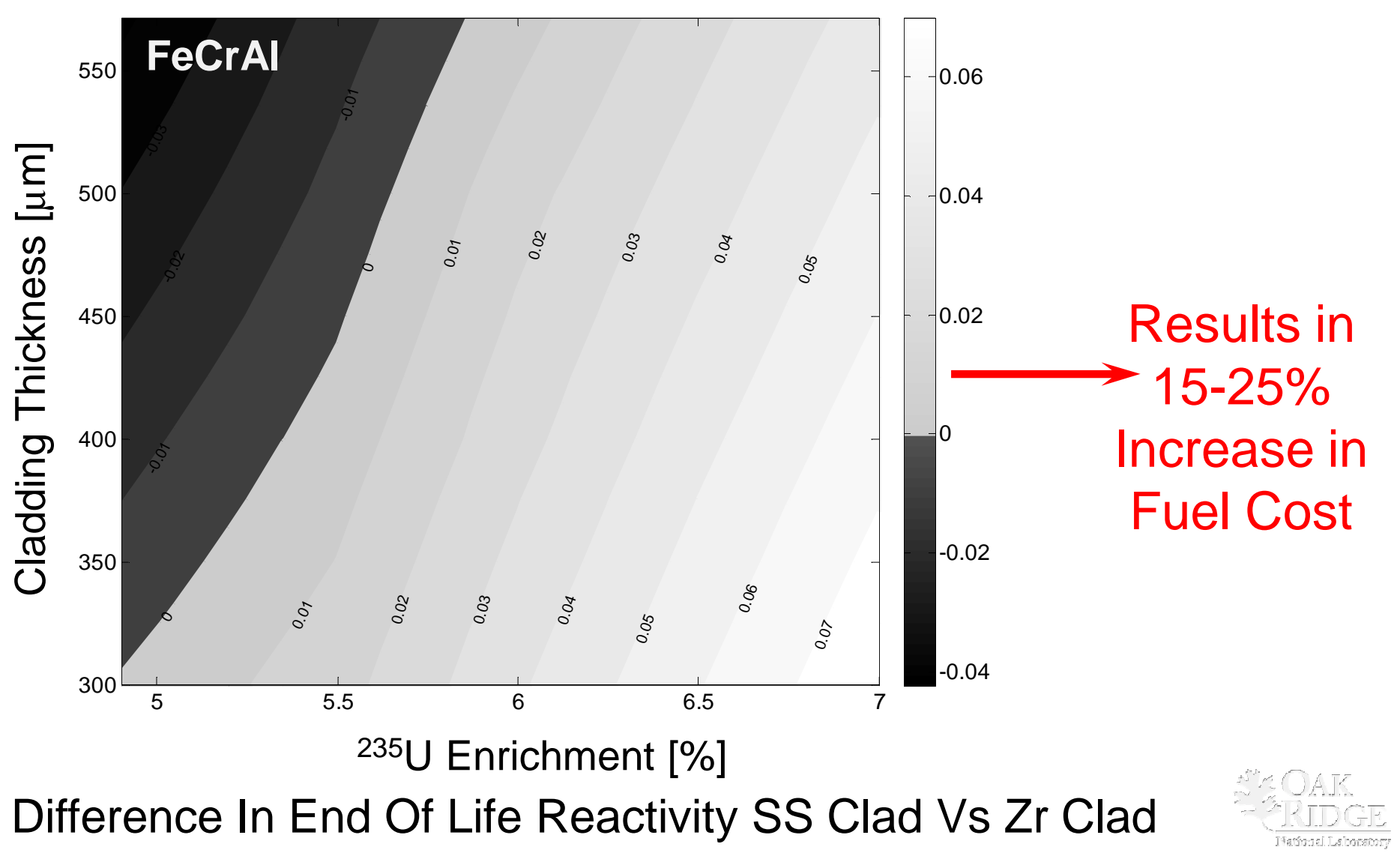




\section{Several Accident Tolerant Fuel Concepts are Under Consideration, including:}

- $\mathrm{UO}_{2}$ - Zircaloy (Base Case)

- $\mathrm{UO}_{2}-\mathrm{FeCrAl}$ (oxidation resistant Steel)

- $\mathrm{FCM}$ - FeCrAl Fully Ceramic Microencapsulated Fuel

Conventional $\mathrm{LWR}_{\mathrm{UO}} \mathrm{R}_{2} \mathrm{Rod}$

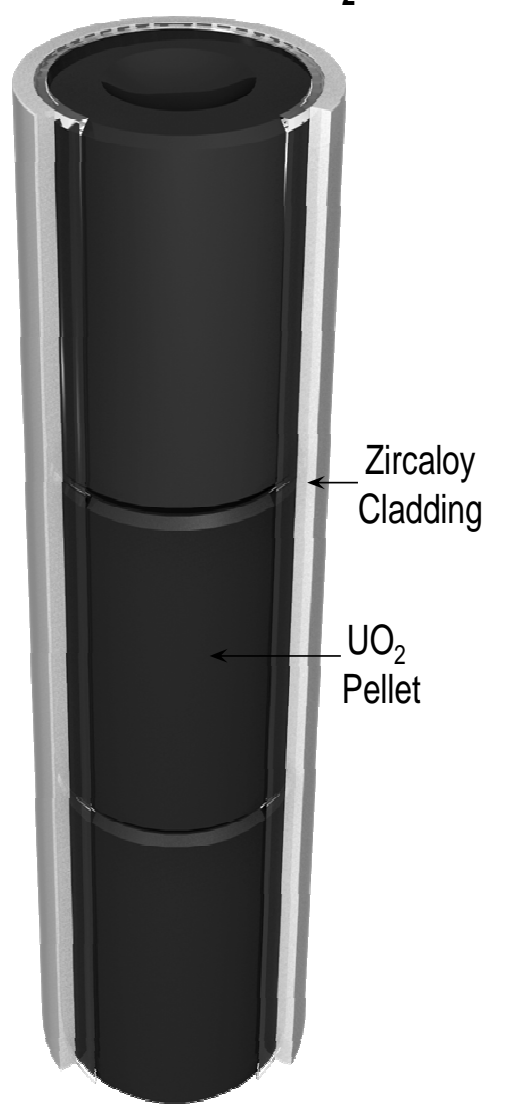

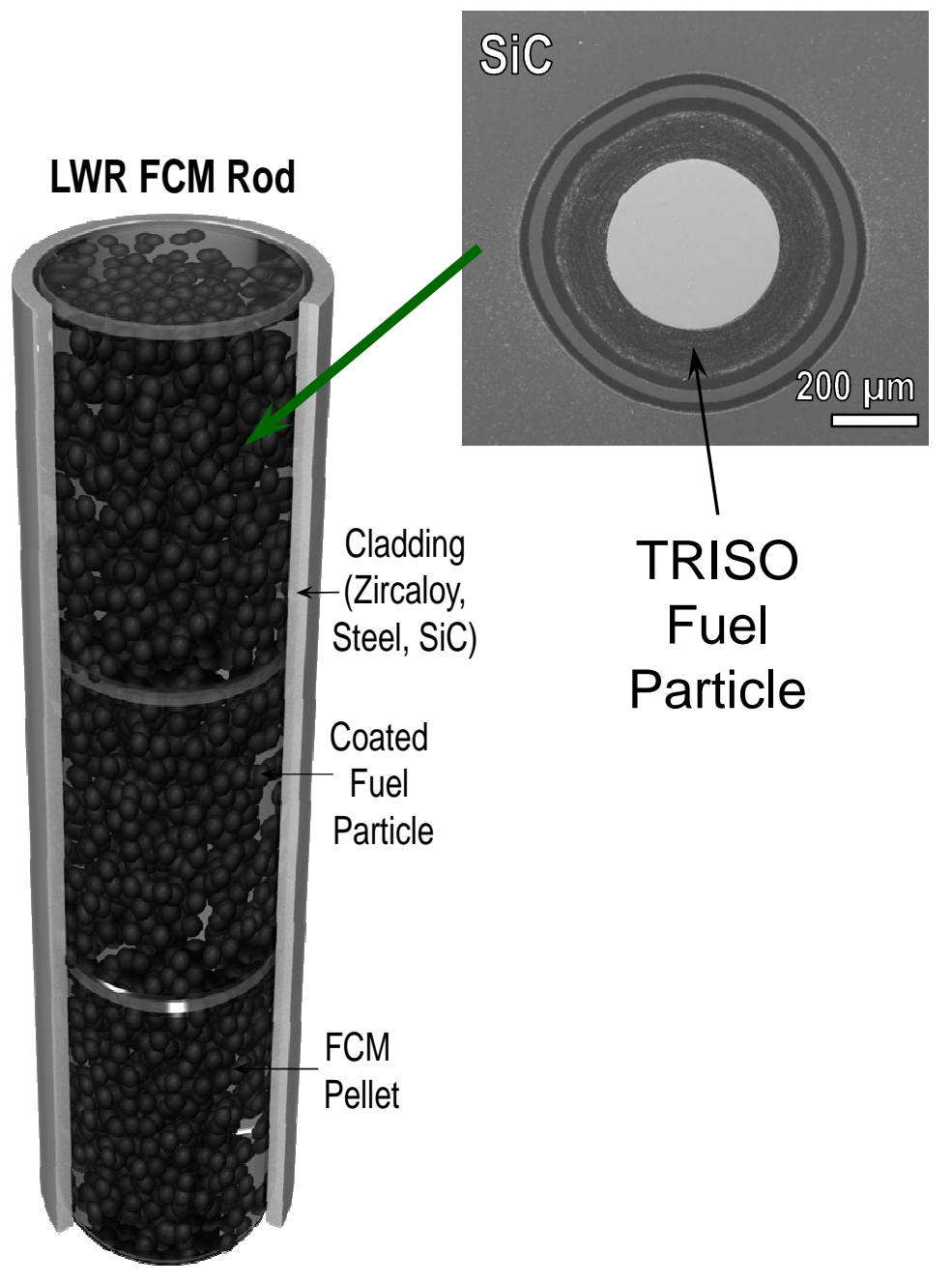

Improved oxidation-resistant Zr cladding (coatings or alloys) is also being considered 


\section{Conclusions}

- A high density of nanoscale dispersoids in ferritic/martensitic and austenitic steels is a promising approach to simultaneously achieve improved radiation resistance and high temperature strength

- Ultrahigh densities approaching $10^{24} / \mathrm{m}^{3}$ may provide dramatic improvements

- Computational thermodynamics is a convenient tool for rapidly developing high performance alloys

- Several options exist that may provide improved accident-tolerant fuel cladding for light water fission reactors compared to existing Zr alloy cladding 